OPEN ACCESS

Edited by:

Sven Saussez,

University of Mons, Belgium

Reviewed by:

Tina Dalianis,

Karolinska Institutet (KI), Sweden

Jerome R. Lechien,

University of Mons, Belgium

${ }^{*}$ Correspondence:

Sjoerd H. van der Burg

shvdburg@/umc.nl

Specialty section:

This article was submitted to

Head and Neck Cancer,

a section of the journal

Frontiers in Oncology

Received: 24 March 2020 Accepted: 16 November 2020

Published: 21 December 2020

Citation:

Welters MJP, Santegoets SJ and van der Burg SH (2020) The Tumor

Microenvironment and

Immunotherapy of Oropharyngeal

Squamous Cell Carcinoma.

Front. Oncol. 10:545385.

doi: 10.3389/fonc.2020.545385

\section{The Tumor Microenvironment and Immunotherapy of Oropharyngeal Squamous Cell Carcinoma}

\author{
Marij J. P. Welters, Saskia J. Santegoets and Sjoerd H. van der Burg * \\ Medical Oncology, Oncode Institute, Leiden University Medical Center, Leiden, Netherlands
}

Oropharyngeal squamous cell carcinoma (OPSCC) develops as a consequence of several mutations in the tumor suppressor pathways or after a progressive infection with high risk human papillomavirus (HPV). The dismal side effects of the current standard of care and the clear involvement of the immune system has led to a surge in clinical trials that aim to reinforce the tumor-specific immune response as a new treatment option. In this review, we have focused on the most recent literature to discuss the new findings and insights on the role of different immune cells in the context of OPSCC and its etiology. We then applied this knowledge to describe potential biomarkers and analyzed the rationale and outcomes of earlier and ongoing immunotherapy trials. Finally, we describe new developments that are still at the preclinical phase and provide an outlook on what the near future may bring, now that several new and exciting techniques to study the immune system at the single cell level are being exploited.

Keywords: tumor microenvironment, immunotherapy, oropharyngeal cancer, $\mathrm{T}$ cells, myeloid cells, clinical outcome, survival

\section{INTRODUCTION}

Head and neck cancer is the sixth most prevalent cancer type and mainly consists of squamous cell carcinoma [90\%; HNSCC $(1,2)]$. The tumor can develop in the oral cavity, the larynx, pharynx (hypopharynx, nasopharynx, or oropharynx) and in the sinonasal tract. While the incidence of head and neck cancer located at most oral sites is marginally decreasing due to the knowledge of tobacco and alcohol as risk factors for its development, the incidence of oropharyngeal carcinomas is increasing, especially in the developed world (3). Oropharyngeal squamous cell carcinomas (OPSCC) include oropharyngeal, tonsillar and base-of-tongue tumors. A high percentage (60$80 \%$ ) of the OPSCC are induced by high risk human papillomavirus type 16 (HPV16) (4-6). Patients with HPV+ OPSCC often tend to be younger, approximately $75 \%$ is male, a minority smokes and they often have lymph node metastasis when first visiting the clinic $(7,8)$. HPV is a double stranded DNA virus encoding for early and late (envelop) proteins $(9,10)$. The early proteins E6 and E7 are oncoproteins and responsible for the malignant transformation of HPV infected epithelial cells and maintenance hereof $(11,12)$. Patients with HPV16+ OPSCC display a longer overall survival (OS) and a lower recurrence rate after standard of care treatment than patients with HPV-negative OPSCC $(13,14)$.

Only recently the difference between these two OPSCC entities has been acknowledged and a debate on treatment has been started $(15,16)$. To understand the differences between the 
$\mathrm{HPV}+$ and HPV-negative tumors, in-dept analysis have been performed on various levels including genetics (DNA), epigenetics, (micro)RNA and the immune system (7). De-intensified treatment, by lowering the dose of the (chemotherapeutic) drug or radiotherapy or by replacement of the drug, have been suggested in order to decrease side effects particularly in patients with $\operatorname{HPV}+\operatorname{OPSCC}(15,16)$. This led to inferior survival and new treatment designs are required (17). Immunotherapy may form a new effective treatment in OPSCC and is currently under investigation. While it is clear that during HPV infection and subsequent transformation several ways are exploited to escape from the immune system (18-22), HPV16 E6/E7-specific T-cells are often detected in OPSCC tumors and their presence is associated with improved clinical outcome (6, $23,24)$. In addition, a whole series of articles exists on the association between intratumoral T-cell infiltration and better clinical outcome after standard of care therapy (25-28). These type of data paved the way for immunotherapeutic strategies to harness the immune response to OPSCC. Indeed, blockade of CTLA-4 and/or PD-1 has been studied and showed a survival benefit in a subset of patients with different types of HNSCC when compared to the standard of care treatment arm (29). The vast majority of patients did not benefit from this treatment, illustrating the requirement for in-depth studies on systemic and local host-tumor interactions. In particular, studies on the tumor immune microenvironment (TME) are a prerequisite to understand what hurdles are at play and need to be overcome in order for the immune system to effectively control tumor growth.

A search in PubMed using the key terms "Oropharyngeal cancer immunity", "Oropharyngeal cancer myeloid cells", "Oropharyngeal cancer immunotherapy trial", and "Head and Neck squamous cell carcinoma immunotherapy trial" was performed for articles published in the last 10 years (until august 2020) describing cohorts of patients with head and neck cancer, of which at least $25 \%$ had OPSCC and the results were not typical for one type of HNSCC, or with $<25 \%$ of OPSCC patients but with results specific for the OPSCC group. Also, studies comparing the results between HPV-negative and HPV-positive HNSCC were included. In addition, a search in Clinicaltrials.gov for registered and ongoing trials in patients with HNSCC, including OPSCC, was performed. From these articles a selection was made to discuss the insights and developments in OPSCC immunity, biomarkers, and immunotherapy within the last decade. Last but not least, these studies were supplemented with general literature to explain concepts.

\section{THE TUMOR IMMUNE MICROENVIRONMENT}

The TME plays a pivotal role in the clinical behavior and response to different sorts of therapy of various cancer types (30). In-depth studies on the type, balance and interaction of immune cells in the TME and how this may affect clinical behavior could open the door to rationally designed strategies to treat patients with OPSCC (23).

\section{Lymphocytes}

The influx of high number of $\mathrm{T}$ cells was positively associated with clinical outcome of OPSCC after standard of care therapy $(23,31-33)$. In particular, strong infiltration by CD8+ and CD4+ $\mathrm{T}$ cells in pretreatment OPSCC tissues was associated with lower $\mathrm{T}$ stage, improved disease specific survival (DSS) and prolonged overall survival (OS). The clinical benefit of tumor infiltration with T cells was irrespective of HPV status of the tumor, albeit that HPV-induced tumors were more often strongly infiltrated by these $\mathrm{T}$ cells $(31,34-38)$. The functional activity of these tumor-infiltrating $\mathrm{T}$ cells is also important. Higher interferon gamma (IFN $\gamma$ ) and lower interleukin-4 (IL-4) and transforming growth factor-beta (TGF- $\beta$ ) cytokine expression levels were observed in HPV+ than HPV-negative OPSCC (39). In line with this, HPV-induced OPSCC contain high numbers of IFN $\gamma$ or IL-17 producing CD8+ T cells (40) and the presence of IFN $\gamma$ producing CD4+ and CD8+ T cells in OPSCC, as inferred by the expression of the transcription factor T-box (Tbet) expressed in $\mathrm{T}$ cells, was related to better OS (6). Interestingly, the presence of IL-17-producing non-T cells in HPV+ OPSCC was associated with worse clinical benefit (38).

The analysis of freshly dissociated OPSCC tissues by mass cytometry revealed that HPV16+ OPSCC, comprising HPV16specific $\mathrm{T}$ cells, also contained high numbers of CD161+ classical $\mathrm{T}$ cells, CD103+ tissue resident CD8+ T cells, dendritic cells (DCs) and DC-like macrophages (6). CD161+ T cells were highly activated, as shown by the high expression levels of PD-1, CD38 and HLA-DR, and were shown to be superior effector cells as they produced more IFN $\gamma$ per cell (24). Notably, a higher frequency of CD161+CD4+ T cells was found to be associated with prolonged survival in OPSCC (24). The abundant presence of CD103+CD8+ T cells in HPV16+ OPSCC and its correlation with better prognosis was also demonstrated by others $(41,42)$. These CD103+CD8+ T cells represent non-circulating memory $\mathrm{T}$ cells that play a key role in local immunosurveillance (43) and are enriched for a number of genes associated with tissue resident cells (44). Single cell RNA analysis of 13 OPSCC revealed that these cells also expressed genes associated with cytotoxic potential, exhaustion/co-inhibition programmed cell death protein 1 (PD-1), lymphocyte activation gene 3 (LAG3), and $\mathrm{T}$ cell immunoglobulin and mucin domain-containing protein 3 (TIM3)) as well as activation/co-stimulation [CD27, inducible T cell costimulator (ICOS) and tumor necrosis factor receptor superfamily member 14 (TNFRSF14)] (45).

An important aspect in tumor control by $\mathrm{T}$ cells is the interaction with human leukocyte antigen (HLA) molecules presenting tumor-derived antigens at the cell surface of tumor cells, yet HLA expression is often lost or decreased in OPSCC $(46,47)$. Antigen presentation to CD8+ T cells may also be impaired by alterations in antigen processing pathway components such as the endoplasmic reticulum aminopeptidase 1 (ERAP1), an enzyme involved in trimming the N-terminus of peptide until it fits in the HLA class I molecule. Some polymorphisms in ERAP-1 were associated with high or low $\mathrm{T}$ cell infiltration of OPSCC. Interestingly, only the ERAP1 allotypes present in highly infiltrated HPV16+ OPSCC were capable of trimming model 
antigens, including HPV16 E7, to the proper HLA class I binding epitope (48). In contrast to HPV-negative OPSCC, there is no correlation between HLA class I expression and survival for HPV+ $\operatorname{OPSCC}(49,50)$. The expression of HLA class II, which was more often found on tumor cells in HPV+ OPSCC, is associated with longer OS, DFS and disease specific survival (DSS) in OPSCC (46), supporting a role for CD4+ T cells in the control of OPSCC.

\section{The Curious Relationship Between Regulatory T Cells and OPSCC Survival}

Regulatory $\mathrm{T}$ cells (Tregs) act as gatekeepers of immunological tolerance, and dysfunction in Treg-mediated control plays an important role in autoimmune and allergic disorders and cancer. Tregs play a dismal role in tumor immunity, with numerous studies revealing their role in suppressing anti-tumor immune responses and promoting tumor progression in various types of cancer. In HNSCC, including OPSCC, there is conflicting evidence regarding their role in suppressing tumor immunity and survival (51). In two small scale studies, a negative impact on clinical outcome and disease progression was observed for high frequencies of Tregs in the peripheral blood of patients with OPSCC $(52,53)$, whereas other studies including OPSCC demonstrated no impact of tumor-infiltrating Tregs (54) or a positive impact of circulating or tumor-infiltrating Tregs $(38,55$, 56) on clinical outcome and/or survival. A similar debate has been described for colorectal cancers $(57,58)$, resulting in the definition of three populations of CD4+Foxp3+ T cells, namely highly suppressive CD45RA-negative Foxp $3^{\text {hi }}$ effector Tregs (Foxp $3^{\text {hi }}$ eTregs), suppressive CD45RA+Foxp ${ }^{\text {int }}$ naïve Tregs (Foxp $3^{\text {int }}$ nTregs), and non-suppressive cytokine-producing CD45RA-negative Foxp $3^{\text {int }} \mathrm{T}$ cells (59-61). Patients with colorectal tumors that were predominantly infiltrated with non-suppressive and cytokine-producing CD45RA-negative Foxp $3^{\text {int }} \mathrm{T}$ cells displayed a much better survival than patients with tumors mainly infiltrated with suppressive Foxp $3^{\text {hi }}$ eTregs (60). This phenomenon may also play a role in studies that evaluated the clinical significance of intratumoral Tregs in OPSCC by means of immunohistochemistry (IHC), since discrimination between Foxp $3^{\text {int }}$ and Foxp $3^{\text {hi }}$ is difficult using this technique.

Part of the controversy on the prognostic value of Tregs may also be attributed to differences in the type of samples assessed, i.e. peripheral blood versus tumor tissues, and the absence of knowledge about the HPV status of the assessed tumors (51). The latter may be important as HPV-associated OPSCC is a distinct clinical entity with a different intratumoral immune cell make-up and a much better prognosis after (chemo)radiotherapy than HPV-negative OPSCC, particularly in patients with a concomitant HPV-specific and type 1-oriented intratumoral $\mathrm{T}$ cell response $(6,14,32,62)$.

Alternatively, differences in the effects of Tregs on clinical outcome may also come from their functional adaptability. Tregs can mirror effector cells by adopting the transcriptional profile of the cells they aim to suppress. In mice, Foxp3+ Tregs have been described to upregulate signal transducer and activator of transcription 3 (STAT3), GATA binding protein 3 (GATA-3)/ interferon regulatory factor 4 (IRF4), or Tbet to control T helper type 17 (Th17), Th2 or Th1 inflammatory responses, respectively, in persistent infection and autoimmunity (63-66). We recently described that Tbet+ Tregs accumulate in tumors of HPV16+ OPSCC patients, and that their presence was associated with prolonged survival following standard of care therapy (67). Albeit detected at lower levels, the number of infiltrating Tbet+ Tregs strongly correlated with the number of tumor-infiltrating Tbet-positive CD4+ and CD8+ effector T cells as well as with the detection of HPV16-specific T cells, both of which we previously demonstrated to be associated with better tumor control on standard of care therapy. These data suggested that Tbet expression within the intratumoral Treg population and the association with prolonged survival is merely the reflection of an ongoing beneficial Th1-oriented T cell response, and that the balance between pro- and anti-tumor $\mathrm{T}$ cells eventually determines clinical outcome.

\section{Myeloid Cells}

The myeloid cell compartment constitutes another major player in the TME. One of the most abundant types of myeloid cells in the TME are macrophages. High numbers of tumor associated macrophages (TAMs) in the TME is most often associated with poor prognosis $(68,69)$. Macrophages are highly plastic and display a functional status ranging between classically activated anti-tumor type 1 macrophages (M1) and the alternatively activated tumor promoting type 2 macrophages (M2) (70). Incoming monocytes from the blood into the tumor can differentiate into macrophages dependent on the different cytokines they sense and the interactions they have with other cells present in the TME. While an inflamed TME with IFN $\gamma$ results in M1 differentiation, high levels of interleukin 4 (IL-4) and IL-13 turn them into M2 (71). M2 can produce cytokines, such as TGF- $\beta$, vascular endothelial growth factor (VEGF), IL-6, IL-10, and prostaglandin E2 (PGE2), and chemokines that promote angiogenesis or destruct the extracellular matrix, thereby helping tumor cells to invade and metastasize and they can stimulate Treg development and expansion while suppressing CD8+ T cell function $(72,73)$. Moreover, in response to inflammation (IFN $\gamma$ production) or hypoxia TAMs can upregulate inhibitory receptor ligands for T cells like PDL-1 and PDL-2 $(69,72)$.

CD68+CD163+ M2 macrophages are often detected in OPSCC $(46,74)$. A higher infiltration with these macrophages was associated with poor clinical outcome in two studies on HNSCC tumors with the majority or all being OPSCC $(46,75)$. The strong stromal presence of CD68+CD163+ macrophages was associated with shorter DFS, DSS and OS, independent of HPV status in OPSCC (46), but this does not mean that all macrophages are bad as high infiltration with macrophages, the minority being $\mathrm{M} 2$, was associated with better PFS in p16+ OPSCC (47). This suggests that other macrophages may benefit tumor control. Indeed, in various tumor types high infiltration with M1 (CD14+CD163-negative) macrophages is associated with prolonged survival $(76,77)$. It also implies that simply depleting all macrophages in the TME may have detrimental 
effects and even accelerate tumor growth or increase recurrences $(72,78,79)$. Therefore, reprogramming TAMs is currently under investigation in solid tumors, to move the balance from protumorigenic towards tumor fighting macrophages $(72,80)$ and it is highly likely that also a strong Th1 cell response may aid in this process (73).

Similar to TAMs also myeloid derived suppressor cells (MDSCs) can be recruited from the blood or generated locally by arresting monocytes in their immature state. The phenotype of these MDSC is often described as CD14+ HLA-DR-CD33+ $\mathrm{CD} 11 \mathrm{~b}+(81,82)$, hence monocytic MDSC (mMDSC). High circulating numbers of these cells are associated with metastasis and recurrences in OPSCC patients (83). Interestingly, treatment with tadalafil, a phospohodiesterase 5 inhibitor to block nitric oxide and arginase 1 production by myeloid cells, resulted in the activation of a stronger tumor-specific T-cell response with no difference in responsiveness between HPV16+ OPSCC and HPV-negative (non)oropharyngeal cancer patients (84). Several other studies to deplete mMDSCs, prevent their recruitment or block their suppressive function have been undertaken (85). Next to these mMDSC also granulocytic MDSC (gMDSC) and neutrophils may enter the tumor to suppress effector $\mathrm{T}$ cells in the TME. However, no studies on the role of these cells in the TME of OPSCC have been reported.

Finally, recruited monocytes can also differentiate into DCs. High numbers of CD14+CD11b+CD11c+ DC-like macrophages and CD14-negative CD11b ${ }^{\text {dim }} \mathrm{CD} 11 \mathrm{c}+$ DCs have been detected in the TME of OPSCC patients with a good clinical outcome (6). In another study, high numbers of stromal CD11c+ DC was an independent prognostic factor for better survival in HNSCC, including OPSCC (55). Current studies have analyzed DCs by only a few markers. Recently, two in-depth studies on blood derived DCs have divided these in several phenotypic and functional subtypes $(86,87)$. We applied high-dimensional flow cytometry and multispectral imaging to reveal a new subset of DCs, called CD163 + cDC2 or DC3, the presence of which was directly related to survival in HPV16+ OPSCC (74). Moreover, these DCs displayed the capacity to specifically trigger type $1 \mathrm{~T}$ cell responses by their production of IL-12 and IL-18 (74) and may be involved in conferring a tissue-resident signature to stimulated $\mathrm{T}$ cells (88).

\section{Expression of Immune Checkpoints}

Intratumoral $\mathrm{T}$ cell reactivity is regulated via so-called costimulatory and co-inhibitory (or checkpoint) molecules. Wellknown is the suppression of $\mathrm{T}$ cells expressing $\mathrm{PD}-1$ via $\mathrm{PD}-1$ ligand (PD-L1) and blockade of this axis has resulted in spectacular clinical responses for a number of tumor types. Analyses of checkpoint expression in OPSCC revealed that the expression of PD-1 and/or PD-L1 was related to a stronger immune infiltration and good prognosis after standard therapy (89-92), most likely as it reflects an ongoing immune response in which type I and II interferons are produced. The presence of intratumoral PD-L1 expressing CD68+ macrophages and CD8+ $\mathrm{T}$ cells was found to be associated with improved OS (93). In addition, rich immune infiltration, comprising $\mathrm{PD} 1+\mathrm{CD} 8+\mathrm{T}$ cells and CD68+ macrophages, was found to be associated with a better clinical response to checkpoint therapy (94). While the numbers of infiltrating total CD8 $+\mathrm{T}$ cells and CD68+ macrophages were higher in HPV+ OPSCC, the percentage of CD8+PD-1+ T cells was similar, and the percentage of CD68+ $\mathrm{PD}-\mathrm{L} 1+$ macrophages lower in $\mathrm{HPV}+$ OPSCC compared to HPV-negative OPSCC (95).

Another actionable co-inhibitory molecule is natural killer group 2 member A (NKG2A) $(96,97)$, which together with its co-receptor CD94 is expressed by many of the tumor-infiltrating CD8+ T cells and only by a minority of the CD4+ T cells in OPSCC (45). Remarkably, NKG2A expression on CD8+ in OPSCC is independent from PD-1 and often found on CD103+ early effector tissue resident CD8+ T cells $(45,97)$. The frequency of intratumoral NKG2A/CD94+ CD8+ $\mathrm{T}$ cells was higher in in HPV16+ OPSCC patients with a demonstrable ongoing HPV16specific T cell response when compared to HPV16+ OPSCC lacking such an anti-tumor response or to HPV-negative OPSCC patients $(6,97)$. NKG2A interacts with HLA-E, which is a non-classical highly-conserved HLA class I molecule that is expressed by many cancers $(96,98,99)$, including OPSCC (50). The interaction between NKG2A and HLA-E is thought to block the cytotoxic activity of CD8+ T cells and NK cells (100) and a couple of studies have shown that expression of HLA-E by tumor cells restrained the prognostic impact of tumor-infiltrating CD8+ T cells $(98,99)$, including that of HPV16+ OPSCC (97).

Other inhibitory receptors found to be upregulated on activated $\mathrm{T}$ cells in the TME of OPSCC include TIM3, LAG3 and $\mathrm{T}$ cell immunoreceptor with Ig and ITIM domains (TIGIT) and others (45). All expressed on higher numbers of $\mathrm{T}$ cells in $\mathrm{HPV}+$ when compared to virus-negative head and neck tumors, but only in HPV+ tumors each of these markers was associated with prolonged survival (101).

Overall, the expression of inhibitory receptors are more indicative for an inflamed TME with ongoing antitumor immunity than for an exhausted $\mathrm{T}$ cell response in OPSCC. Nevertheless, the interaction between inhibitory receptors and their ligands will inhibit the activation and effector functions of $\mathrm{T}$ cells impairing their capacity to control OPSCC growth.

\section{THE BLOOD COMPARTMENT FOR BIOMARKER ANALYSIS}

An important question is whether the TME biomarkers associated with clinical outcome are also detectable and prognostic when analyzed on immune cells present in blood, as this compartment is easily accessible and allows for kinetic studies. The easiest approach is to determine differential leukocyte counts on blood samples, which is used in all hospitals as a normal diagnostic routine. High neutrophil counts in OPSCC, and more specifically high neutrophil-tolymphocyte ratio (NLR) in the blood sample prior, during and after radiotherapy correlated with poor OS, recurrence free survival (RFS) and/or DSS as well as distant metastasis (102105). Also, in HPV16+ OPSCC patients, a high NLR in the blood sample obtained prior to concurrent chemoradiation correlated with decreased OS. Neutrophils appear to have an unique 
phenotype of immature granulocytes CD11 $\mathrm{c}^{\text {bright }} / \mathrm{CD} 62 \mathrm{~L}^{\mathrm{dim}} /$ CD11b $b^{\text {bright }} / \mathrm{CD} 16^{\text {bright }}$, which are absent in blood of healthy donors (106).

High circulating monocyte counts prior to therapy also correlated to reduced OS and RFS in HPV16+ OPSCC patients $(102,107)$. While monocyte counts in HPV-negative OPSCC patients were even higher, the absolute monocyte counts were not related to clinical outcome in this patient group (102), suggesting that these monocytes might have a negative impact only in highly immunogenic tumors. Potentially, the composition of the monocyte subtypes may be of importance as some of them may constitute CD14+ MDSC, which have shown to exhibit immune suppressive effects $(6,108)$. Furthermore, the percentage of classical (CD14 ${ }^{\text {high }} \mathrm{CD} 16$-negative) monocytes were shown to be increased in OPSCC patients as well as expressed PD-L1 (107). Also a high monocyte-to-lymphocyte ratio was associated with lower OS in OPSCC $(107,109)$.

So far, no comparative studies have been performed with respect to neutrophils and MDSC in order to analyze if the blood compartment reflects the TME.

The relation between higher numbers of tumor-infiltrating $\mathrm{T}$ cells and clinical outcome prompts the question if this can also be detected in the blood. High pre-treatment numbers of $\mathrm{CD} 8+\mathrm{T}$ cells in the blood correlated with improved OS in HPV16+ OPSCC patients (14). However, absolute CD4 counts as well as frequencies of $\mathrm{CD} 4+\mathrm{T}$ cells measured in blood of OPSCC was not correlating to clinical outcome (14). This seems logical as the population of CD4+ $\mathrm{T}$ cells comprises naïve $\mathrm{T}$ cells, type 1 and type 2 effector $\mathrm{T}$ cells, memory $\mathrm{T}$ cells and also Tregs which dilutes the real impact of one of these subpopulations. Moreover, the peripheral blood levels of $\mathrm{CD} 4+$ and CD8+ T cells were not related to the type and degree of specific $T$ cell subset infiltration in OPSCC (34). Interestingly, it was found that HPV+ OPSCC with elevated Treg frequencies in the blood displayed a better OS than patients with HPV-negative tumors or patients with HPV+ OPSCC patients displaying relatively low numbers of circulating Tregs (56).

Last but not least, HPV16-specific T cells have been detected in the circulation of patients with OPSCC using functional assays in which PBMC were stimulated with the HPV-encoded antigens (110-112). The detection of such an HPV16-specific T cell response in the peripheral blood did not always coincide with the presence of these HPV16-specific T cells in the TME, this (110). HPV16-specific T cells could also be detected in a large percentage of healthy individuals (113-115) indicating that their presence is not enough to function as a biomarker.

All together there are a couple of opportunities (neutrophils, monocytes, Tregs) that may be exploited as blood biomarkers reflecting the TME, but more sophisticated measurements of subpopulations and validation of the used techniques are warranted.

\section{THE ROLE OF TUMOR-SPECIFIC T CELLS IN THE TME OF OPSCC}

There is ample evidence that tumors highly infiltrated with CD4 + and/or CD8+ T cells (also referred to as immunologically "hot" tumors) respond better to (immuno-)therapy $(27,116)$. In OPSCC, HPV infection may play a very important role in this phenomenon. Superior prognosis of HPV+ OPSCC over HPVnegative OPSCC following chemoradiotherapy has been reported $(13,117)$. Interestingly, for the majority of HPV+ OPSCC this was related with a more dense and activated $\mathrm{T}$ cell infiltrate, suggesting a role for HPV-specific immunity in tumor control $(14,62,118)$.

HPV16+ tumors express the virally derived oncoproteins E6 and E7, and it has been suggested that these "non-self" HPV antigens can evoke immune responses. Indeed, cellular and humoral immunity against these antigens can be detected in the peripheral blood and TME of HPV16+ OPSCC patients (110, 119-123). Notably, there is a direct link between the presence of an intratumoral HPV-specific T-cell response and the good prognosis of HPV16-driven OPSCC (6). Patients with an HPV16-driven tumor and a concomitant intratumoral HPV16specific $T$ cell response have a much better survival after (chemo) radiotherapy than patients with an HPV16-driven tumor without such an HPV16-specific $\mathrm{T}$ cell response or patients with HPV-negative OPSCC. Moreover, the presence of these HPV-specific T cells was associated with a type 1 oriented TME and a much higher level of activated CD161-expressing effector memory CD4+ T cells, CD103+ tissue-resident CD8+ T cells, and tissue-resident memory T cell-stimulating $\mathrm{CD} 163+\mathrm{CDC} 2(6,74)$.

Although a clear relation could be found between the dense, type 1 oriented HPV-specific immune infiltrate and disease outcome in HPV16-driven OPSCC, there is also evidence for improved survival of HPV-negative OPSCC patients with strongly T-cell infiltrated tumors $(37,124)$. Unfortunately, knowledge on the tumor-specificity is lacking in these studies. A promising and emerging field in studies of the anti-tumor response is the recognition of tumor neoantigens. Tumors with high numbers of nonsynonymous mutations have a greater likelihood of presenting mutation-derived neoepitopes and consequently mounting a T-cell response against these epitopes thereby improving the clinical response (125). Tumor mutational burden (TMB) in HNSCC is relatively high and comparable to other smoking related tumor types. Viral HNSCC display only half of the mutations rate observed in non-viral HNSCC (125, 126). CD8+ T cells responding to such mutations have been detected in a few patients with non-OPSCC either spontaneously induced (127) or following a complete response after pembrolizumab treatment (128). Notably, such neoantigen specific T cells can also be detected in low TMB tumors (129), suggesting that they may also be present in OPSCC.

\section{IMMUNOTHERAPY IN OPSCC}

During the last two decades, several strategies aiming to boost the immune response to cancer have been developed and tested in patients with cancer, ranging from immune modulators to checkpoint therapy, adoptive cell transfer, and vaccines. Table 1 summarizes active/recruiting immunotherapy trials in patients with OPSCC and HNSCC, including OPSCC. 


\section{Immune Modulators}

One of the earliest immune stimulators tested is recombinant IL2 (rIL-2), used to directly stimulate the activity of tumor-specific $\mathrm{T}$ cells. In a phase III trial with 200 patients rIL-2 was injected close to the ipsilateral lymph node, each day for 10 days before surgery and radiotherapy and then each month at the contralateral LN site for 1 year. The treatment had no significant side effects but improved the DFS (from 51 to $64 \%$ ) and OS (from 55 to $73 \%$ ) at 5 years (130). At a later stage, IRX-2 was developed to stimulate T cell activity. IRX-2 is a mix of purified cytokines obtained after stimulating peripheral blood mononuclear cells (PBMC) with phytohemagglutinin (PHA). In a phase IIa trial treatment naïve patients with HNSCC received subcutaneous IRX-2 injections near the TDLN for 10 days prior to surgical resection, which with the knowledge of today is an interesting choice as our studies showed that the great majority of TDLN comprise tumor-specific $\mathrm{T}$ cells even when they are hardly detectable in the tumor itself $(24,131)$. Injection of IRX-2 was associated with small radiological reductions in tumor size, including patients with OPSCC (132). In a first analysis, pre-andpost IRX-2 samples were analyzed and showed marked increases in CD3 + T cells and CD68+ macrophages (133). In a subgroup of 7 patients pre-and post-samples could be compared, showing potential increases in CD4+ T cells (6/7) and CD68 macrophages $(4 / 7)$ as well as decreases in CD8+ T cells (5/7) patients after IRX-2 treatment. Unfortunately, HPV status was not determined but one could envision that most of the responders would have a HPV-positive tumor. Nanostring analyses using the PanCancer IO360 immune profiling panel confirmed the increases in CD4+ $\mathrm{T}$ cells and most markedly in DC as well as in the immune modulatory cytokines IL-6 and IL-10 (134). Another compound that indirectly could stimulate the tumor-specific $\mathrm{T}$ cell response is the toll-like receptor 8 (TLR8) agonist motolomid, which is known to activate monocytes, DCs and NK cells (135). Treatment of recurrent or metastatic HNSCC patients after the first 6 cycles of chemotherapy with weekly infusions of cetuximab with or without motolomid did not result in improved OS in a trial with $\mathrm{n}=195$ patients. However, in a prespecified subgroup of $n=83$ OPSCC patients the motolomid arm displayed longer PFS and OS when the tumor was induced by HPV (136), suggesting that motolomid may have boosted the existing but probably weak HPV-specific $\mathrm{T}$ cell response in these patients.

Other compounds target immune suppressive cells that are active in the TME. For instance, metformin, which is widely used as a drug to manage diabetes type 2 , has been described to have anti-cancer effects (137). In mice, metformin increased the number of tumor infiltrating CD8+ $\mathrm{T}$ cells, and the combination of metformin and a tumor vaccine improved the multifunctionality of the vaccine-induced CD8+ tumor infiltrating lymphocytes (TIL) (138). Another potential mechanism is the effect of metformin on Tregs, as it also inhibits mammalian target of rapamycin (mTOR). Metformin treatment for a minimum of 9 days before surgery of HNSCC, more than half being OPSCC, resulted in a strong decrease of intratumoral Foxp3+ Tregs and increase of stromal CD8+ T cells between pre-and post-treatment samples $(n=16 \mathrm{HPV}+$ and $n=20$ HPV-negative), independent of HPV status (139). Potentially, metformin treatment may be interesting for HPV+ OPSCC patients with ongoing tumor immunity. As high numbers of Tregs have infiltrated those tumors (67), the use of metformin may tip the balance in favor of spontaneous anti-tumor responses in these patients, resulting in tumor shrinkage. Similarly, it may provide benefit in combination with other types of immunotherapy. Several new immune modulators are currently tested in the clinic (Table 1).

\section{Checkpoint Blockade Therapy}

The use of antibodies that block the interaction between PD-1 and PD-L1 are successfully used in several types of immunogenic cancers with a high mutation rate (e.g. melanoma, lung cancer) or induced by the Merkel cell virus (140-142). Several studies have been reported on the efficacy of such antibodies for the treatment of HNSCC, including patients with OPSCC (143-147).

In CheckMate 141, a phase III trial, platinum-resistant patients with recurrent or metastatic tumors were treated with the anti-PD-1 antibody nivolumab. The response rate was $13.3 \%$ in the nivolumab group versus $5.8 \%$ in patients treated with standard of care. The objective response rate (ORR) to nivolumab was $15.9 \%$ in $\mathrm{HPV}+$ patients while it was $8.0 \%$ in HPV-negative patients (143). The 2-year OS in this study was $16.9 \%$ in patients with PD-L1 expression, regardless of the HPV status (148). Nivolumab also induced clinical benefit in patients lacking PD-L1 expression, albeit in a lower proportion of patients (148). Interestingly, continued treatment of patients with nivolumab with slow progressing disease still resulted in clinical benefit, irrespective of the HPV status of the tumor. This was associated with a decrease in the percentage of PD-1+ Tregs in PBMC (149), suggesting that an ongoing immune response was present in these patients but which was simply too weak to be effective. Importantly, nivolumab treatment improved OS irrespective of prior treatment with cetuximab, an antibody known for its immune modulating side effects (150-153), albeit that the reduction in risk of death was lower in pre-treated patients (154). A similar response rate with PD-1 blockade using pembrolizumab was found in the KEYNOTE-012 phase Ib study of 60 patients with recurrent or metastatic tumors with PD-L1 expression. In total $18 \%$ of the patients displayed a clinical response, divided as 25\% (4/16) in the HPV+ HNSCC patient group and 14\% (4/29) in HPV-negative group (144).

The PD-L1 antibody durvalumab was tested in the expansion phase of a phase I/II study for treatment of patients with recurrent or metastatic tumors, $40 \%$ of which were HPV+. The ORR was $6.5 \%(4 / 62)$ in the total group with $15 \%$ in the PD-L1 expressing subgroup and $2.6 \%$ in the group with low PD-L1 expression. None of the HPV+ patients showed a response (145).

Another important checkpoint molecule is NKG2A. Preclinical experiments revealed that anti-NKG2A therapy promoted tumor immunity and synergized with PD-1 blockade. In addition, it was shown that NKG2A blockade 
TABLE 1 | Immunotherapy in patients with OPSCC.

\begin{tabular}{|c|c|c|c|c|c|c|c|c|c|c|}
\hline $\begin{array}{l}\text { NCT } \\
\text { number }\end{array}$ & Phase & $\begin{array}{l}\text { Number } \\
\text { of arms }\end{array}$ & Randomized & Treatment & Target & Setting & $\begin{array}{l}\text { Previous } \\
\text { therapy }\end{array}$ & $\begin{array}{l}\text { Number } \\
\text { of } \\
\text { patients }\end{array}$ & Endpoint & $\begin{array}{l}\text { Trial } \\
\text { Status }\end{array}$ \\
\hline OPSCC & \multicolumn{10}{|c|}{ Immune modulators } \\
\hline 2002182 & 2 & 2 & $\begin{array}{l}\text { No (open } \\
\text { label) }\end{array}$ & $\begin{array}{l}\text { ADXS11-0001 vs control } \\
\text { (SoC) }\end{array}$ & ADXS11-0001: HPV16 E7 & $\begin{array}{l}\text { Neoadjuvant } \\
\text { (pre-surgery) }\end{array}$ & None & 30 HPV+ & Safety + IR & $\begin{array}{l}\text { Active (Not } \\
\text { recruiting) }\end{array}$ \\
\hline 4106362 & 2 & 2 & $\begin{array}{l}\text { Yes (open } \\
\text { label) }\end{array}$ & $\begin{array}{l}\text { RT-CT + Cetuxi vs RT- } \\
\text { CT }\end{array}$ & Cetuxi: anti EGFR & First line & None & $\begin{array}{l}70 \mathrm{HPV}+ \\
\mathrm{KRA} \\
\text { variant+ } \\
\text { stage III-IV }\end{array}$ & $\begin{array}{l}\text { Efficacy + } \\
\text { toxicity }\end{array}$ & Recruiting \\
\hline 4508829 & 2 & 1 & $\begin{array}{l}\text { No (open } \\
\text { label) }\end{array}$ & $\begin{array}{l}\text { IMRT + CT + anti EGFR } \\
\text { moAb }\end{array}$ & Anti EGFR & Concurrent & $\begin{array}{l}\text { SoC (no } \\
\text { RT) }\end{array}$ & $\begin{array}{l}52 \\
\text { (advanced } \\
\text { stage) }\end{array}$ & Efficacy & Recruiting \\
\hline OPSCC & \multicolumn{10}{|c|}{ Checkpoints (+ combinations) } \\
\hline 3144778 & 1 & 2 & $\begin{array}{l}\text { Yes (open } \\
\text { label) }\end{array}$ & Durva vs Durva + Treme & $\begin{array}{l}\text { Durva: anti PD-L1 } \\
\text { Treme: anti CTLA-4 }\end{array}$ & $\begin{array}{l}\text { Durva + } \\
\text { Treme prior } \\
\text { to surgery }\end{array}$ & None & $\begin{array}{l}28 \text { stage } \\
\text { II-IVA }\end{array}$ & Safety + IR & $\begin{array}{l}\text { Active (not } \\
\text { recruiting) }\end{array}$ \\
\hline 3618134 & $1 / 2$ & 1 & $\begin{array}{l}\text { No (open } \\
\text { label) }\end{array}$ & $\begin{array}{l}\text { RT + Durva vs RT + } \\
\text { Durva + Treme }\end{array}$ & $\begin{array}{l}\text { Durva: anti PD-L1 } \\
\text { Treme: anti CTLA-4 }\end{array}$ & $\begin{array}{l}\text { Prior to } \\
\text { surgery }\end{array}$ & None & $\begin{array}{l}82 \mathrm{HPV}+ \\
\text { stage I-III }\end{array}$ & $\begin{array}{l}\text { Safety + } \\
\text { efficacy }\end{array}$ & Recruiting \\
\hline 3715946 & 2 & 1 & $\begin{array}{l}\text { No (open } \\
\text { label) }\end{array}$ & RT (reduced) + Nivo & Nivo: anti PD-1 & Adjuvant & Surgery & $\begin{array}{l}135 \\
\text { (primary } \\
\text { tumor) }\end{array}$ & Efficacy & Recruiting \\
\hline \multirow[t]{2}{*}{3799445} & 2 & 1 & $\begin{array}{l}\text { No (open } \\
\text { label) }\end{array}$ & Ipi + Nivo + RT & Ipi: anti CTLA-4 & First line & None & $\begin{array}{l}180 \mathrm{HPV}_{+} \\
\text {stage I- } \\
\text { IVA }\end{array}$ & $\begin{array}{l}\text { Safety + } \\
\text { efficacy }\end{array}$ & Recruiting \\
\hline & & & & Nivo: anti PD-1 & & & & & & \\
\hline 3838263 & 2 & 2 & $\begin{array}{l}\text { Yes }(2: 1 ; \\
\text { open label) }\end{array}$ & Nivo vs CRT (control) & Nivo: anti PD-1 & $\begin{array}{l}\text { Nivo before } \\
\text { RT-CT }\end{array}$ & None & $61 \mathrm{HPV}+$ & $\begin{array}{l}\text { Safety }+ \\
\text { efficacy }\end{array}$ & Recruiting \\
\hline 3811015 & $2 / 3$ & $\begin{array}{l}3 \text { (incl. } \\
\text { cross } \\
\text { over) }\end{array}$ & $\begin{array}{l}\text { Yes (open } \\
\text { label) }\end{array}$ & $\begin{array}{l}\text { IMRT + CT + Nivo vs } \\
\text { IMRT + CT (control) }\end{array}$ & Nivo: anti PD-1 & $\begin{array}{l}\text { Nivo post } \\
\text { RT-CT }\end{array}$ & None & $744 \mathrm{HPV}_{+}$ & $\begin{array}{l}\text { Efficacy + } \\
\text { Prognostic } \\
\text { biomarker }\end{array}$ & Recruiting \\
\hline 3952585 & $2 / 3$ & 3 & $\begin{array}{l}\text { Yes (open } \\
\text { label) }\end{array}$ & $\begin{array}{l}\text { IMRT + CT vs IMRT } \\
\text { (reduced) + CT vs Nivo + } \\
\text { IMRT (reduced) + CT }\end{array}$ & Nivo: anti PD-1 & $\begin{array}{l}\text { Nivo prior to } \\
\text { IMRT } \\
\text { (reduced) + } \\
\text { CT }\end{array}$ & None & $711 \mathrm{p} 16+$ & Efficacy & Recruiting \\
\hline OPSCC & ACT & & & & & & & & & \\
\hline 4015336 & 2 & 1 & $\begin{array}{l}\text { No (open } \\
\text { label) }\end{array}$ & E7 TCR T cells & E7 TCR T cells: HPV16 E7 & HLA-A0201 & None & $\begin{array}{l}180 \\
\text { HPV16+ } \\
\text { stage II-III }\end{array}$ & Safety & Recruiting \\
\hline OPSCC & \multicolumn{10}{|c|}{ Vaccines (+ combinations) } \\
\hline 3258008 & 2 & 1 & $\begin{array}{l}\text { No (open } \\
\text { label) }\end{array}$ & Utomi + ISA101b & $\begin{array}{l}\text { Utomi: agonistic CD137 } \\
\text { ISA101b: HPV16 E6E7 }\end{array}$ & Adjuvant & SoC & $27 \mathrm{HPV}+$ & $\begin{array}{l}\text { Efficacy }+ \\
\text { toxicity }\end{array}$ & $\begin{array}{l}\text { Active (not } \\
\text { recruiting) }\end{array}$ \\
\hline 3669718 & 2 & 2 & $\begin{array}{l}\text { Yes (Double } \\
\text { blinded) }\end{array}$ & $\begin{array}{l}\text { ISA101b + Cemip vs } \\
\text { Cemip }\end{array}$ & $\begin{array}{l}\text { ISA101b: HPV16 E6E7 } \\
\text { Cemip: anti PD-1 }\end{array}$ & Adjuvant & SoC & $\begin{array}{l}194 \\
\text { HPV16+ } \\
\text { R/M }\end{array}$ & $\begin{array}{l}\text { Efficacy }+ \\
\text { toxicity }\end{array}$ & Recruiting \\
\hline 4001413 & 2 & 2 & $\begin{array}{l}\text { Yes (open } \\
\text { label) }\end{array}$ & $\begin{array}{l}\text { Durva vs Durva + } \\
\text { MEDI0457 }\end{array}$ & $\begin{array}{l}\text { Durva: anti PD-L1 } \\
\text { MEDI0457: HPV16/18 } \\
\text { E6E7 }\end{array}$ & Adjuvant & SoC & $66 \mathrm{HPV}+$ & $\begin{array}{l}\text { Efficacy + } \\
\text { toxicity }\end{array}$ & Recruiting \\
\hline HNSCC & \multicolumn{10}{|c|}{ Immune modulators } \\
\hline 3088059 & 2 & Multiple & $\begin{array}{l}\text { No (open } \\
\text { label) }\end{array}$ & $\begin{array}{l}\text { Afatinib, Palbociclib, } \\
\text { Niraparib, Rogaratinib } \\
\text { (BAY1163877) }\end{array}$ & $\begin{array}{l}\text { Afatinib: kinase inhibitor } \\
\text { Palbociclib: kinase } \\
\text { inhibitor } \\
\text { Niraparib: PARP inhibitor } \\
\text { Rogaratinib: FGFR } \\
\text { tyrosine kinase inhibitor }\end{array}$ & Adjuvant & $\mathrm{CT}$ & $340 \mathrm{R} / \mathrm{M}$ & $\begin{array}{l}\text { Efficacy + } \\
\text { Biomarker }\end{array}$ & Recruiting \\
\hline 3795610 & 2 & 1 & $\begin{array}{l}\text { No (open } \\
\text { label) }\end{array}$ & IPI-549 & IPI-549: PI3Ky inhibitor & $\begin{array}{l}\text { Neoadjuvant } \\
\text { (pre-surgery) }\end{array}$ & None & $\begin{array}{l}15 \\
\text { advanced }\end{array}$ & $\begin{array}{l}\text { Pl3Ky } \\
\text { changes + } \\
\text { IR + } \\
\text { toxicity }\end{array}$ & Recruiting \\
\hline HNSCC & \multicolumn{10}{|c|}{ Checkpoints (+ combinations): Ipilimumab } \\
\hline 1935921 & 1 & 1 & $\begin{array}{l}\text { No (open } \\
\text { label) }\end{array}$ & Ipi + cetuxi +RT & $\begin{array}{l}\text { Ipi: anti CTLA-4 } \\
\text { Cetuxi: anti EGFR }\end{array}$ & Concurrent & None & $\begin{array}{l}19 \text { stage } \\
\text { III-IV }\end{array}$ & $\begin{array}{l}\text { Dose } \\
\text { finding + } \\
\text { efficacy + } \\
\text { biomarkers }\end{array}$ & $\begin{array}{l}\text { Active (not } \\
\text { recruiting) }\end{array}$ \\
\hline
\end{tabular}


TABLE 1 | Continued

\begin{tabular}{|c|c|c|c|c|c|c|c|c|c|c|}
\hline $\begin{array}{l}\text { NCT } \\
\text { number }\end{array}$ & Phase & $\begin{array}{l}\text { Number } \\
\text { of arms }\end{array}$ & Randomized & Treatment & Target & Setting & $\begin{array}{l}\text { Previous } \\
\text { therapy }\end{array}$ & $\begin{array}{l}\text { Number } \\
\text { of } \\
\text { patients }\end{array}$ & Endpoint & $\begin{array}{l}\text { Trial } \\
\text { Status }\end{array}$ \\
\hline HNSCC & \multicolumn{10}{|c|}{ Checkpoints (+ combinations): Nivolumab } \\
\hline 2741570 & 3 & 2 & $\begin{array}{l}\text { Yes (open } \\
\text { label) }\end{array}$ & Nivo + ipi vs SoC & $\begin{array}{l}\text { Nivo: anti PD-1 } \\
\text { Ipi: anti CTLA-4 }\end{array}$ & First line & None & 947 R/M & Efficacy & $\begin{array}{l}\text { Active (not } \\
\text { recruiting) }\end{array}$ \\
\hline 2764593 & 1 & 4 & $\begin{array}{l}\text { No (open } \\
\text { label) }\end{array}$ & $\begin{array}{l}\text { Nivo + CT + IMRT, Nivo } \\
+ \text { high CT + IMRT, Nivo } \\
+ \text { Cetuxi + RT, Nivo + } \\
\text { IMRT }\end{array}$ & $\begin{array}{l}\text { Nivo: anti PD-1 } \\
\text { Cetuxi: anti EGFR }\end{array}$ & $\begin{array}{l}\text { Neoadjuvant } \\
\text { (pre-RT) }\end{array}$ & None & $\begin{array}{l}40 \text { stage } \\
\text { I-IV }\end{array}$ & Toxicity & $\begin{array}{l}\text { Active (not } \\
\text { recruiting) }\end{array}$ \\
\hline 2823574 & 2 & 2 & $\begin{array}{l}\text { Yes (double } \\
\text { blinded) }\end{array}$ & $\begin{array}{l}\text { Nivo }+ \text { ipi vs nivo } \\
\text { (control) }\end{array}$ & $\begin{array}{l}\text { Nivo: anti PD-1 } \\
\text { Ipi: anti CTLA-4 }\end{array}$ & Adjuvant & None & $675 \mathrm{R} / \mathrm{M}$ & Efficacy & $\begin{array}{l}\text { Active (not } \\
\text { recruiting) }\end{array}$ \\
\hline 2834013 & 2 & & $\begin{array}{l}\text { No (open } \\
\text { label) }\end{array}$ & $\begin{array}{l}\text { Nivo + ipi vs nivo } \\
\text { (control) }\end{array}$ & $\begin{array}{l}\text { Nivo: anti PD-1 } \\
\text { Ipi: anti CTLA-4 }\end{array}$ & Adjuvant & SoC & $\begin{array}{l}818 \text { PD } \\
\text { (rare } \\
\text { tumors) }\end{array}$ & $\begin{array}{l}\text { Efficacy + } \\
\text { toxicity }\end{array}$ & Recruiting \\
\hline 3247712 & $1 / 2$ & 4 & $\begin{array}{l}\text { No (open } \\
\text { label) }\end{array}$ & Nivo + RT & Nivo: anti PD-1 & $\begin{array}{l}\text { Neoadjuvant } \\
\text { (pre-surgery) }\end{array}$ & None & $\begin{array}{l}28 \text { (eligible } \\
\text { for } \\
\text { surgery) }\end{array}$ & $\begin{array}{l}\text { Safety }+ \\
\text { feasibility + } \\
\text { efficacy }\end{array}$ & Recruiting \\
\hline 3317327 & $1 / 2$ & 1 & $\begin{array}{l}\text { No (open } \\
\text { label) }\end{array}$ & Nivo & Nivo: anti PD-1 & $\begin{array}{l}\text { Neoadjuvant } \\
\text { (pre-RT) }\end{array}$ & SoC & $20 \mathrm{R}$ & $\begin{array}{l}\text { Safety + } \\
\text { efficacy }\end{array}$ & Recruiting \\
\hline 3341936 & 2 & 1 & $\begin{array}{l}\text { No (open } \\
\text { label) }\end{array}$ & Nivo + Liri & $\begin{array}{l}\text { Nivo: anti PD-1 } \\
\text { Liri: anti KIR2DL1/2L3 }\end{array}$ & $\begin{array}{l}\text { Neoadjuvant } \\
\text { (pre-salvage } \\
\text { surgery) }\end{array}$ & SoC & $58 \mathrm{R}$ & $\begin{array}{l}\text { Safety + } \\
\text { efficacy }\end{array}$ & Recruiting \\
\hline 3406247 & 2 & 2 & $\begin{array}{l}\text { No (open } \\
\text { label) }\end{array}$ & Nivo alone vs nivo + ipi & $\begin{array}{l}\text { Nivo: anti PD-1 } \\
\text { Ipi: anti CTLA-4 }\end{array}$ & Adjuvant & $\begin{array}{l}\text { Salvage } \\
\text { surgery } \\
\text { after RT }\end{array}$ & $140 \mathrm{P} / \mathrm{R}$ & $\begin{array}{l}\text { Safety + } \\
\text { efficacy }\end{array}$ & $\begin{array}{l}\text { Not yet } \\
\text { recruiting }\end{array}$ \\
\hline 3620123 & 2 & 2 & $\begin{array}{l}\text { Yes (open } \\
\text { label) }\end{array}$ & Nivo + ipi vs docetaxel & $\begin{array}{l}\text { Nivo: anti PD-1 } \\
\text { Ipi: anti CTLA-4 }\end{array}$ & Palliative & SoC & $280 \mathrm{R} / \mathrm{M}$ & Efficacy & Recruiting \\
\hline 3854032 & 2 & 2 & $\begin{array}{l}\text { Yes (open } \\
\text { label) }\end{array}$ & $\begin{array}{l}\text { Nivo + BMS-986205 vs } \\
\text { Nivo }\end{array}$ & $\begin{array}{l}\text { Nivo: anti PD-1 } \\
\text { BMS-986205: IDO1 } \\
\text { inhibitor }\end{array}$ & $\begin{array}{l}\text { Neoadjuvant } \\
\text { (pre-surgery) }\end{array}$ & None & $\begin{array}{l}48 \text { stage } \\
\text { II-IV (non } \\
\text { R) }\end{array}$ & $\begin{array}{l}\text { Efficacy + } \\
\mathrm{IR}+ \\
\text { toxicity }\end{array}$ & Recruiting \\
\hline 4080804 & 2 & 3 & $\begin{array}{l}\text { Yes (open } \\
\text { label) }\end{array}$ & $\begin{array}{l}\text { Nivo + ipi vs nivo + } \\
\text { Relatlimab vs nivo }\end{array}$ & $\begin{array}{l}\text { Nivo: anti PD-1 } \\
\text { Ipi: anti CTLA4 } \\
\text { Relatlimab: anti LAG3 }\end{array}$ & $\begin{array}{l}\text { Neoadjuvant } \\
\text { (pre-surgery) }\end{array}$ & None & $\begin{array}{l}60 \\
\text { advanced }\end{array}$ & $\begin{array}{l}\text { Safety + IR } \\
+ \text { efficacy }\end{array}$ & Recruiting \\
\hline HNSCC & \multicolumn{10}{|c|}{ Checkpoints (+ combinations): Pembrolizumab } \\
\hline 2296684 & 2 & 1 & $\begin{array}{l}\text { No (open } \\
\text { label) }\end{array}$ & Pembro & Pembro: anti PD-1 & $\begin{array}{l}\text { Neoadjuvant } \\
\text { (pre-surgery) }\end{array}$ & None & $\begin{array}{l}66 \text { stage } \\
\text { III-IV }\end{array}$ & $\begin{array}{l}\text { Efficacy }+ \\
\text { toxicity }\end{array}$ & Recruiting \\
\hline 2586207 & 1 & 1 & $\begin{array}{l}\text { No (open } \\
\text { label) }\end{array}$ & Pembro + CRT & Pembro: anti PD-1 & Concomitant & SoC & $\begin{array}{l}57 \text { stage } \\
\text { III-IV }\end{array}$ & $\begin{array}{l}\text { Safety + } \\
\text { QoL }\end{array}$ & $\begin{array}{l}\text { Active (not } \\
\text { recruiting) }\end{array}$ \\
\hline 2707588 & 2 & 2 & $\begin{array}{l}\text { Yes (open } \\
\text { label) }\end{array}$ & $\begin{array}{l}\text { Pembro + RT vs Cetuxi + } \\
\text { RT } \\
\text { Cetuxi: anti EGFR }\end{array}$ & $\begin{array}{l}\text { Pembro: anti PD-1 } \\
\text { p16/HPV }\end{array}$ & Concomitant & SoC & $\begin{array}{l}133 \\
\text { advanced }\end{array}$ & $\begin{array}{l}\text { Efficacy + } \\
\text { toxicity + } \\
\text { QoL } \\
+ \text { impact }\end{array}$ & $\begin{array}{l}\text { Active (not } \\
\text { recruiting) }\end{array}$ \\
\hline 2718820 & $1 / 2$ & 1 & $\begin{array}{l}\text { No (open } \\
\text { label) }\end{array}$ & Pembro + docetaxel & Pembro: anti PD-1 & Adjuvant & SoC & $22 \mathrm{R} / \mathrm{M}$ & $\begin{array}{l}\text { Efficacy + } \\
\text { QoL + } \\
\text { toxicity }\end{array}$ & $\begin{array}{l}\text { Active (not } \\
\text { recruiting) }\end{array}$ \\
\hline 2769520 & 2 & 1 & $\begin{array}{l}\text { No (open } \\
\text { label) }\end{array}$ & Pembro & Pembro: anti PD-1 & Adjuvant & Surgery & $45 R$ & $\begin{array}{l}\text { Efficacy + } \\
\text { toxicity }\end{array}$ & Recruiting \\
\hline 2775812 & 1 & 1 & $\begin{array}{l}\text { No (open } \\
\text { label) }\end{array}$ & Pembro + CT + IMRT & $\begin{array}{l}\text { Pembro: anti PD-1 } \\
\text { CT: cisplatin }\end{array}$ & Concomitant & SoC & $\begin{array}{l}37 \text { stage } \\
\text { III-IV (high } \\
\text { risk) }\end{array}$ & $\begin{array}{l}\text { RP2D + } \\
\text { efficacy + } \\
\text { toxicity }+ \\
\text { biomarkers }\end{array}$ & $\begin{array}{l}\text { Active (not } \\
\text { recruiting) }\end{array}$ \\
\hline 2777385 & 2 & 2 & $\begin{array}{l}\text { Yes (open } \\
\text { label) }\end{array}$ & Pembro + CT + IMRT & $\begin{array}{l}\text { Pembro: anti PD-1 } \\
\text { CT: cisplatin }\end{array}$ & Adjuvant & SoC & 90 (non M) & $\begin{array}{l}\text { Efficacy + } \\
\text { toxicity }\end{array}$ & Recruiting \\
\hline 2819752 & 1 & 2 & $\begin{array}{l}\text { No (open } \\
\text { label) }\end{array}$ & Pembro + CRT & Pembro: anti PD-1 & Concomitant & SoC & $\begin{array}{l}36 \text { stage } \\
\text { IV (HPV+ } \\
\text { vs HPV-) }\end{array}$ & $\begin{array}{l}\text { MTD + } \\
\text { toxicity + } \\
\text { efficacy }\end{array}$ & $\begin{array}{l}\text { Active (not } \\
\text { recruiting) }\end{array}$ \\
\hline 2841748 & 2 & 2 & $\begin{array}{l}\text { Yes (double- } \\
\text { blinded) }\end{array}$ & Pembro vs placebo & Pembro: anti PD-1 & Adjuvant & SoC & $\begin{array}{l}100 \text { stage } \\
\text { III-IV (high } \\
\text { risk) }\end{array}$ & Efficacy & Recruiting \\
\hline 3082534 & 2 & 4 & $\begin{array}{l}\text { No (open } \\
\text { label) }\end{array}$ & Pembro + Cetuxi & $\begin{array}{l}\text { Pembro: anti PD-1 } \\
\text { Cetuxi: anti EGFR }\end{array}$ & Concurrent & SoC & 83 R/M & Efficacy & Recruiting \\
\hline
\end{tabular}


TABLE 1 | Continued

\begin{tabular}{|c|c|c|c|c|c|c|c|c|c|c|}
\hline $\begin{array}{l}\text { NCT } \\
\text { number }\end{array}$ & Phase & $\begin{array}{l}\text { Number } \\
\text { of arms }\end{array}$ & Randomized & Treatment & Target & Setting & $\begin{array}{l}\text { Previous } \\
\text { therapy }\end{array}$ & $\begin{array}{l}\text { Number } \\
\text { of } \\
\text { patients }\end{array}$ & Endpoint & $\begin{array}{l}\text { Trial } \\
\text { Status }\end{array}$ \\
\hline 3383094 & 2 & 2 & $\begin{array}{l}\text { Yes (open } \\
\text { label) }\end{array}$ & $\begin{array}{l}\text { Pembro + IMRT vs IMRT } \\
+ \text { CT (control) }\end{array}$ & Pembro: anti PD-1 & $\begin{array}{l}\text { Concurrent } \\
+ \text { adjuvant }\end{array}$ & None & $\begin{array}{l}114 \text { p16+ } \\
\text { stage III-IV }\end{array}$ & $\begin{array}{l}\text { Efficacy }+ \\
\text { toxicity }\end{array}$ & Recruiting \\
\hline 3546582 & 2 & 2 & $\begin{array}{l}\text { Yes (open } \\
\text { label) }\end{array}$ & Pembro + RT vs RT & Pembro: anti PD-1 & Adjuvant & $\mathrm{RT}$ & $\begin{array}{l}102 \mathrm{R} \text { or } \\
\text { second } \\
\text { primary }\end{array}$ & $\begin{array}{l}\text { Safety }+ \\
\text { efficacy }\end{array}$ & Recruiting \\
\hline 3695510 & 2 & 1 & $\begin{array}{l}\text { No (open } \\
\text { label) }\end{array}$ & Afatinib + Pembro & $\begin{array}{l}\text { Afatinib: kinase inhibitor } \\
\text { Pembro: anti PD-1 }\end{array}$ & Adjuvant & SoC & $29 \mathrm{R} / \mathrm{M}$ & $\begin{array}{l}\text { Efficacy + } \\
\text { toxicity }\end{array}$ & Recruiting \\
\hline HNSCC & \multicolumn{10}{|c|}{ Checkpoints (+ combinations): Pembro } \\
\hline 4193293 & $1 / 2$ & 1 & $\begin{array}{l}\text { No (open } \\
\text { label) }\end{array}$ & Duvelisib + pembro & $\begin{array}{l}\text { Duvelisib: PI3K inhibitor } \\
\text { Pembro: anti PD-1 }\end{array}$ & Adjuvant & SoC & $30 \mathrm{R} / \mathrm{M}$ & $\begin{array}{l}\text { DLT + } \\
\text { efficacy + } \\
\text { safety }\end{array}$ & Recruiting \\
\hline HNSCC & \multicolumn{10}{|c|}{ Checkpoints (+ combinations): Durvalumab } \\
\hline 2551159 & 3 & 3 & $\begin{array}{l}\text { Yes (open } \\
\text { label) }\end{array}$ & $\begin{array}{l}\text { Durva vs durva + treme } \\
\text { vs SoC }\end{array}$ & $\begin{array}{l}\text { Durva: anti PD-L1 } \\
\text { Treme: anti CTLA-4 }\end{array}$ & First line & None & $823 \mathrm{R} / \mathrm{M}$ & $\begin{array}{l}\text { Efficacy + } \\
\text { PK + IR + } \\
\text { QoL }\end{array}$ & $\begin{array}{l}\text { Active (not } \\
\text { recruiting) }\end{array}$ \\
\hline 2827838 & 2 & 1 & $\begin{array}{l}\text { No (open } \\
\text { label) }\end{array}$ & Durva & Durva: anti PD-L1 & $\begin{array}{l}\text { Neoadjuvant } \\
\text { (pre-surgery) }\end{array}$ & None & $\begin{array}{l}20 \text { stage } \\
\text { I-IV }\end{array}$ & $\begin{array}{l}\text { IR vs HPV } \\
\text { status }\end{array}$ & Recruiting \\
\hline 2997332 & 1 & 1 & $\begin{array}{l}\text { No (open } \\
\text { label) }\end{array}$ & Durva + CT & Durva: anti PD-L1 & Adjuvant & SoC & $\begin{array}{l}36 \\
\text { advanced }\end{array}$ & $\begin{array}{l}\text { Safety }+ \\
\text { RP2D }\end{array}$ & Recruiting \\
\hline 3051906 & $1 / 2$ & 1 & $\begin{array}{l}\text { No (open } \\
\text { label) }\end{array}$ & Durva + cetuxi + RT & $\begin{array}{l}\text { Durva: anti PD-L1 } \\
\text { Cetuxi: anti EGFR }\end{array}$ & Adjuvant & SoC & $\begin{array}{l}69 \\
\text { advanced }\end{array}$ & $\begin{array}{l}\text { Efficacy + } \\
\text { toxicity }\end{array}$ & $\begin{array}{l}\text { Not yet } \\
\text { recruiting }\end{array}$ \\
\hline 3088059 & 2 & Multiple & $\begin{array}{l}\text { No (open } \\
\text { label) }\end{array}$ & SoC, IPH2201 or durva & $\begin{array}{l}\text { IPH2201: anti NKG2A } \\
\text { Durva: anti PD-L1 }\end{array}$ & Adjuvant & CT & 340 R/M & $\begin{array}{l}\text { Efficacy + } \\
\text { Biomarker }\end{array}$ & Recruiting \\
\hline 3258554 & $2 / 3$ & 2 & $\begin{array}{l}\text { Yes (open } \\
\text { label) }\end{array}$ & $\begin{array}{l}\text { RT + durva vs RT + } \\
\text { cetuxi }\end{array}$ & $\begin{array}{l}\text { Durva: anti PD-L1 } \\
\text { Cetuxi: anti EGFR }\end{array}$ & Adjuvant & SoC & $\begin{array}{l}523 \text { stage } \\
\text { III-IV }\end{array}$ & $\begin{array}{l}\text { DLT + } \\
\text { efficacy } \\
+ \text { QoL }\end{array}$ & Recruiting \\
\hline 3426657 & 2 & 1 & $\begin{array}{l}\text { No (open } \\
\text { label) }\end{array}$ & $\begin{array}{l}\text { Durva + treme }++ \text { CT }+ \\
\text { RT }\end{array}$ & $\begin{array}{l}\text { Durva: anti PD-L1 } \\
\text { Treme: anti CTLA-4 }\end{array}$ & Adjuvant & CT & $\begin{array}{l}120 \\
\text { advanced }\end{array}$ & $\begin{array}{l}\text { Feasibility } \\
+\mathrm{IR}+ \\
\text { toxicity }+ \\
\text { efficacy }\end{array}$ & Recruiting \\
\hline 3509012 & 1 & 8 & $\begin{array}{l}\text { No (open } \\
\text { label) }\end{array}$ & Durva + treme + CRT & $\begin{array}{l}\text { Durva: anti PD-L1 } \\
\text { Treme: anti CTLA-4 }\end{array}$ & Adjuvant & SoC & $\begin{array}{l}360 \\
\text { advanced }\end{array}$ & $\begin{array}{l}\text { Toxicity }+ \\
\text { efficacy }\end{array}$ & $\begin{array}{l}\text { Active (not } \\
\text { recruiting) }\end{array}$ \\
\hline 3529422 & 2 & 1 & $\begin{array}{l}\text { No (open } \\
\text { label) }\end{array}$ & Durva + Treme + RT & $\begin{array}{l}\text { Durva: anti PD-L1 } \\
\text { Treme: anti CTLA-4 }\end{array}$ & Adjuvant & Surgery & $\begin{array}{l}24 \text { stage } \\
\text { III-IV (non } \\
\text { M) }\end{array}$ & $\begin{array}{l}\text { Safety }+ \\
\text { efficacy }\end{array}$ & Recruiting \\
\hline HNSCC & \multicolumn{10}{|c|}{ Checkpoints (+ combinations): others } \\
\hline 2999087 & 3 & 4 & $\begin{array}{l}\text { Yes (open } \\
\text { label) }\end{array}$ & $\begin{array}{l}\text { Avelu + cetuxi + RT vs } \\
\text { cetuxi + RT vs CRT }\end{array}$ & $\begin{array}{l}\text { Avelu: anti PD-L1 } \\
\text { Cetuxi: anti EGFR }\end{array}$ & & None & $\begin{array}{l}688 \\
\text { advanced }\end{array}$ & Efficacy & Recruiting \\
\hline 4129320 & $2 / 3$ & 4 & $\begin{array}{l}\text { Yes (open } \\
\text { label) }\end{array}$ & $\begin{array}{l}\text { Enoblitu + MGA012 vs } \\
\text { Enoblitu + MGA012 + CT } \\
\text { vs MGA012 + CT vs } \\
\text { Pembro + CT (control) }\end{array}$ & $\begin{array}{l}\text { Enoblituzumab: anti B7H3 } \\
\text { (MGA271) } \\
\text { MGA012: anti PD-1 } \\
\text { Pembro: anti PD-1 }\end{array}$ & & None & $750 \mathrm{R} / \mathrm{M}$ & $\begin{array}{l}\text { Efficacy + } \\
\text { toxicity + } \\
\mathrm{IR}+\mathrm{QoL}\end{array}$ & $\begin{array}{l}\text { Not yet } \\
\text { recruiting }\end{array}$ \\
\hline 2274155 & 1 & 3 & $\begin{array}{l}\text { No (open } \\
\text { label) }\end{array}$ & MEDI6469 & MEDI6469: OX40 agonist & $\begin{array}{l}\text { Neoadjuvant } \\
\text { (pre-surgery) }\end{array}$ & None & $\begin{array}{l}17 \\
\text { advanced }\end{array}$ & $\begin{array}{l}\text { Safety }+ \\
\text { feasibility + } \\
\mathrm{IR}+ \\
\text { efficacy }\end{array}$ & $\begin{array}{l}\text { Active (not } \\
\text { recruiting) }\end{array}$ \\
\hline HNSCC & ACT & & & & & & & & & \\
\hline 3083873 & 2 & 5 & $\begin{array}{l}\text { No (open } \\
\text { label) }\end{array}$ & $\begin{array}{l}\text { LN-145 non- } \\
\text { cryopreserved vs } \\
\text { cryopreserved }\end{array}$ & autologous TIL & Adjuvant & SoC & $55 \mathrm{R} / \mathrm{M}$ & $\begin{array}{l}\text { Efficacy + } \\
\text { safety }\end{array}$ & Recruiting \\
\hline 3578406 & 1 & 2 & $\begin{array}{l}\text { Yes (open } \\
\text { label) }\end{array}$ & $\begin{array}{l}\text { TCR-T with or without } \\
\text { anti PD-1 secreting } \\
\text { element }\end{array}$ & HPV16 E6-specific T cells & Adjuvant & SoC & $\begin{array}{l}20 \text { HPV16 } \\
+\mathrm{R} / \mathrm{M}\end{array}$ & MTD & Recruiting \\
\hline HNSCC & \multicolumn{10}{|c|}{ Vaccine (+ combinations) } \\
\hline 1998542 & 2 & 1 & $\begin{array}{l}\text { No (open } \\
\text { label) }\end{array}$ & $\begin{array}{l}\text { AlloVax + CRCL + } \\
\text { AlloStim }\end{array}$ & $\begin{array}{l}\text { AlloVax } \\
\text { CRCL: chaperone rich cell } \\
\text { lysate } \\
\text { AlloStim: adjuvant }\end{array}$ & Adjuvant & SoC & 12 R/M & $\begin{array}{l}\text { Safety + } \\
\text { efficacy }\end{array}$ & Completed \\
\hline
\end{tabular}


TABLE 1 | Continued

\begin{tabular}{|c|c|c|c|c|c|c|c|c|c|c|}
\hline $\begin{array}{l}\text { NCT } \\
\text { number }\end{array}$ & Phase & $\begin{array}{l}\text { Number } \\
\text { of arms }\end{array}$ & Randomized & Treatment & Target & Setting & $\begin{array}{l}\text { Previous } \\
\text { therapy }\end{array}$ & $\begin{array}{l}\text { Number } \\
\text { of } \\
\text { patients }\end{array}$ & Endpoint & $\begin{array}{l}\text { Trial } \\
\text { Status }\end{array}$ \\
\hline 2865135 & $1 b / 2$ & 1 & $\begin{array}{l}\text { No (open } \\
\text { label) }\end{array}$ & DPX-E7 & DPX-E7:HPV16 E7 $1-19$ & Adjuvant & SoC & $\begin{array}{l}44 \mathrm{HPV}+ \\
\mathrm{HLA}-\mathrm{A}^{\star} 02 \\
+\end{array}$ & $\begin{array}{l}\text { Safety + } \\
\text { efficacy }\end{array}$ & $\begin{array}{l}\text { Active (not } \\
\text { recruiting) }\end{array}$ \\
\hline 3162224 & $1 b / 2 a$ & 1 & $\begin{array}{l}\text { No (open } \\
\text { label) }\end{array}$ & MEDI0457 + Durva & $\begin{array}{l}\text { MEDI0457: HPV16/18 } \\
\text { E6E7 } \\
\text { Durva: anti PD-L1 }\end{array}$ & Adjuvant & SoC & $\begin{array}{l}35 \mathrm{HPV}+ \\
\mathrm{R} / \mathrm{M}\end{array}$ & $\begin{array}{l}\text { Safety + } \\
\text { efficacy }\end{array}$ & $\begin{array}{l}\text { Active (not } \\
\text { recruiting) }\end{array}$ \\
\hline 3260023 & $1 b / 2$ & 1 & $\begin{array}{l}\text { No (open } \\
\text { label) }\end{array}$ & TG4001 + Avelu & $\begin{array}{l}\text { TG4001: HPV16 E6E7 } \\
\text { Avelu: anti PD-L1 }\end{array}$ & Adjuvant & SoC & $\begin{array}{l}52 \mathrm{HPV}+ \\
\mathrm{R} / \mathrm{M}\end{array}$ & $\begin{array}{l}\text { Safety + } \\
\text { DLT (+ } \\
\text { efficacy in } \\
\text { phase II) }\end{array}$ & Recruiting \\
\hline 3633110 & $1 / 2$ & 2 & $\begin{array}{l}\text { No (open } \\
\text { label) }\end{array}$ & $\begin{array}{l}\text { GEN-009 vs GEN-009 + } \\
\text { anti PD-1 }\end{array}$ & $\begin{array}{l}\text { GEN-009: neoepitope } \\
\text { SLP vaccine } \\
\text { Anti PD-1: nivo or pembro }\end{array}$ & Adjuvant & SoC & 99 NED & $\begin{array}{l}\text { Safety + IR } \\
+ \text { efficacy }\end{array}$ & $\begin{array}{l}\text { Active (not } \\
\text { recruiting) }\end{array}$ \\
\hline 3946358 & 2 & 1 & $\begin{array}{l}\text { No (open } \\
\text { label) }\end{array}$ & UCPVax + Atezo & UCP: telomerase derived & Adjuvant & SoC & $\begin{array}{l}47 \mathrm{HPV}+ \\
\text { advanced/ } \\
\mathrm{M}\end{array}$ & $\begin{array}{l}\text { Efficacy + } \\
\text { QoL }\end{array}$ & Recruiting \\
\hline 4180215 & $1 / 2$ & Multiple & $\begin{array}{l}\text { No (open } \\
\text { label) }\end{array}$ & $\begin{array}{l}\text { HB-201 (IV or IT) vs HB- } \\
201+\mathrm{Cl}\end{array}$ & HB-201: HPV16 E7E6 & Adjuvant & SoC & $100 \mathrm{HPV}_{+}$ & $\begin{array}{l}\text { Dose } \\
\text { finding + } \\
\text { toxicity }\end{array}$ & Recruiting \\
\hline 4287868 & $1 / 2$ & 2 & $\begin{array}{l}\text { No (open } \\
\text { label) }\end{array}$ & $\begin{array}{l}\text { PDS0101 + M7824 + } \\
\text { NHS-IL12 }\end{array}$ & $\begin{array}{l}\text { PDS0101: HPV } \\
\text { M7824: anti PD-L1/TGF } \beta \\
\text { NHS-IL12: IL12 }\end{array}$ & Adjuvant & SoC & $\begin{array}{l}40 \mathrm{HPV}+ \\
\text { advanced/ } \\
\mathrm{M}\end{array}$ & $\begin{array}{l}\text { Safety + } \\
\text { efficacy }\end{array}$ & Recruiting \\
\hline 4432597 & $1 / 2$ & 4 & $\begin{array}{l}\text { No (open } \\
\text { label) }\end{array}$ & $\begin{array}{l}\text { PRGN-2009 vs PRGN- } \\
2009+\mathrm{M} 7824\end{array}$ & $\begin{array}{l}\text { PRGN-2009: HPV } \\
\text { M7824: anti PD-L1/TGF } \beta\end{array}$ & $\begin{array}{l}\text { Neoadjuvant } \\
\text { or induction }\end{array}$ & SoC & $\begin{array}{l}70 \mathrm{HPV}+ \\
\mathrm{R} / \mathrm{M}\end{array}$ & $\begin{array}{l}\text { Safety + } \\
\text { efficacy }\end{array}$ & Recruiting \\
\hline
\end{tabular}

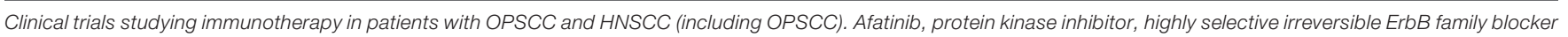

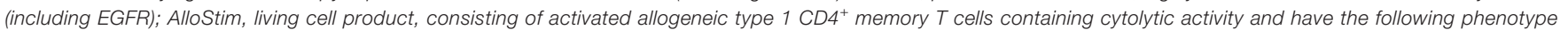

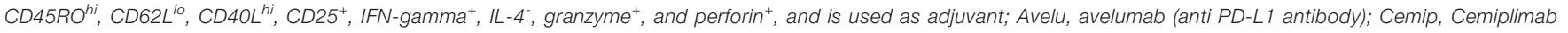

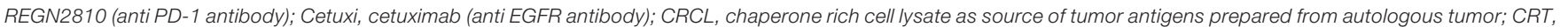

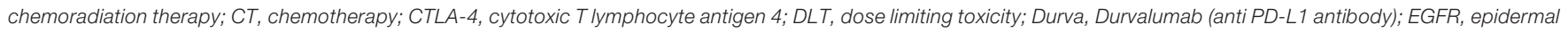

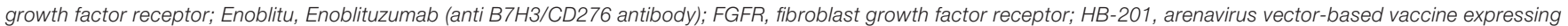

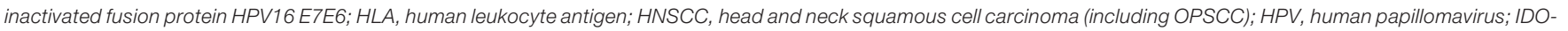

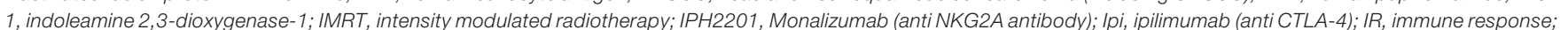

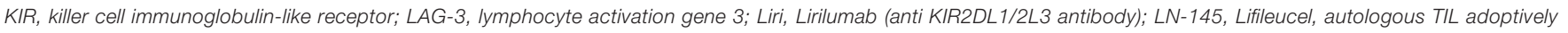

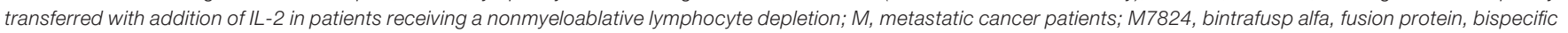

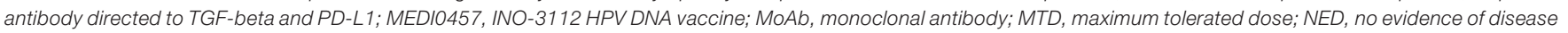

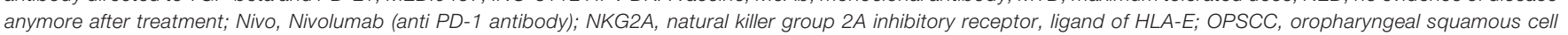

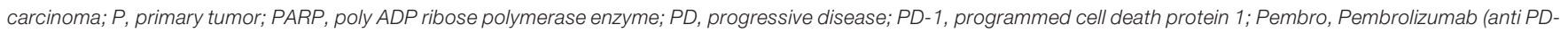

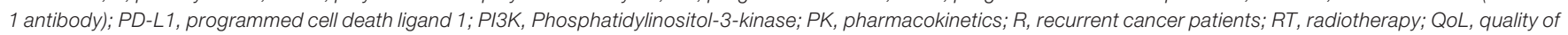

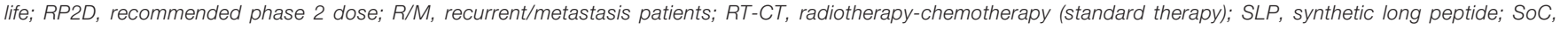

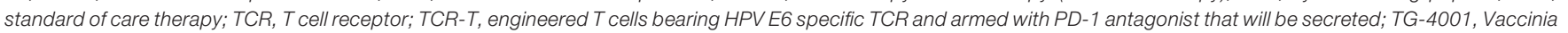

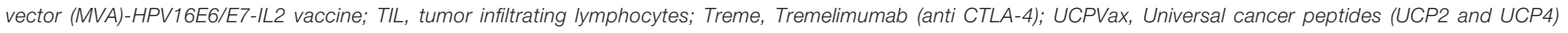
derived from telomerase, a CD4 Thelper type 1 inducer cancer vaccine; Utomi, utomilumab (agonistic anti CD137 antibody).

improved the efficacy of tumor vaccines and adoptive cell therapy (ACT) $(96,97)$. The humanized NKG2A antibody monalizumab was tested together with cetuximab in previously treated recurrent or metastatic tumors, including 32\% OPSCC. A preliminary report on the outcome of the trial revealed a confirmed clinical partial response (PR) in 8 out of 26 patients (31\%) and stable disease (SD) in 14 out of 26 patients, which was regarded as promising when compared to historical cetuximab data (96).

In comparison to the high ORR in virus-driven Merkel cell carcinoma after checkpoint therapy (56\% (142)), the response in $\mathrm{HPV}+$ patients to checkpoint therapy is disappointingly low. However, in view of the fact that patients with both an HPV+ tumor and a strong immune response to HPV display an excellent response to standard of care therapy $(6,24)$, this result was to be expected. The majority of HPV+ patients with recurrent or metastatic tumors most likely are those in whom there was no or a very weak intratumoral T-cell response to HPV during first line treatment and it is known that checkpoint blockade works best in patients with a preexisting tumor-specific immune response (155). Hence, in OPSCC these therapies should be combined with modalities that enhance the tumor-reactive $\mathrm{T}$ cell response in patients.

\section{Adoptive Cell Therapy}

The infusion of large numbers of tumor-reactive $\mathrm{T}$ cells, being either ex-vivo expanded TILs, T-cell receptor (TCR) transduced T cells or chimeric antigen receptor (CAR)-T cells is one way to enhance the number of tumor-reactive $\mathrm{T}$ cells and has proven to be clinically effective in patients with advanced cancer (156-158). The presence of two strong tumor-specific antigens E6 and E7 in 
HPV-driven cancers provides the opportunity to specifically stimulate and expand tumor-specific $\mathrm{T}$ cells for ACT. Stimulation of peripheral blood lymphocytes with overlapping peptide pools resulted in the expansion of HPV16-specific T cells in 33 of 52 HPV16+ OPSCC patients. Most of the cell cultures comprised HPV16-specific CD4+ T cells and infrequently CD8+ T cells with the capacity to kill target tumor cells (122). A highly reproducible method to stimulate these cells under good manufacturing practice (GMP)-conditions resulted in the expansion of IFN $\gamma$-producing HPV-specific CD4+ T cells (11 of 11 cases) and CD8+ T cells ( 3 of 11) cases (131). In a phase II ACT trial, one out of 5 OPSCC patients resolved most of the metastatic lesions (complete response, CR) except for one brain metastasis, which was resected. Responding patients received higher numbers of IFN $\gamma$-producing HPV-specific TILs and the frequency of HPVspecific T cells in the blood one month after ACT correlated with clinical outcome. The question is how HPV-specific ACT will be used as most patients of whom their primary tumors display HPVspecific TIL reactivity respond well to chemoradiation while the tumors of most patients with recurrent disease are expected to contain no or few HPV-specific TILs (6). If present in the tumor, ex-vivo expansion and reinfusion of HPV-specific TIL may help to prevent or to reduce chemoradiation as primary treatment.

The absence of HPV-specific T cells mandates alternative approaches such as the infusion of ex-vivo TCR-transduced autologous $\mathrm{T}$ cells. Draper et al. reported the isolation of an HLA-A 0201 restricted HPV16 E6 29 -38-specific TCR from a patient with HPV16-induced anal cancer. The use of this TCR is expected to contribute to tumor immunity as the tumor site was highly enriched for this TCR clonotype when compared to blood and $\mathrm{T}$ cells transduced with this TCR were shown to recognize several HPV16+ cell lines of different origins (159). Another study reported the isolation of an HLA-DRB1 ${ }^{\star} 04$ restricted TCR reactive to the HPV16 $\mathrm{E}_{70-89}$ epitope. TCRtransduced cells were shown to specifically produce IFN $\gamma$ when stimulated with HPV16 E6 and E7 containing tumor lysate (160). The isolation of TCR responsive to HPV epitopes restricted by a series of HLA class I and II molecules will lead to a warehouse of HPV-specific TCR required for personalized treatment of patients with recurrent or metastatic HPV-induced OPSCC. Currently, the use of T cells transgenic for an E7-specific TCR is tested in the clinic (Table 1). The fact that most mutations (neoantigens) are patient specific makes a similar approach for HPV-negative OPSCC complicated but not impossible (161).

\section{Vaccines}

Therapeutic vaccination is another option to increase the number of tumor-reactive $\mathrm{T}$ cells in OPSCC, preferentially against tumor-specific epitopes created by DNA mutations or oncogenic viruses. Based on a whole series of different trials it was concluded that the induction of tumor reactivity correlated with clinical outcome after vaccination in patients with precancers or in settings of low tumor burden, and with tumor regressions if broad type $1 \mathrm{~T}$ cell reactivity was established (162). The treatment of most established cancers will require the combination of therapeutic vaccination with other modalities to overcome immune suppression and escape (163).
Two types of vaccines, one aiming to induce responses to MAGE-A3 and HPV and the other aiming to induce T-cell reactivity against p53 (for $\mathrm{HPV}$-negative tumors) were tested in groups of HNSCC patients, including 30-40\% OPSCC patients. These vaccines displayed a weak immunogenicity and did not alter clinical outcome $(164,165)$.

However, in a single arm phase II trial, designed based on the observation that HPV16+ OPSCC patients lacking tumor infiltration with HPV16-specific T cells are most likely the ones that are diagnosed with incurable $\operatorname{HPV} 16+$ cancer $(6,24)$ and that PD-1 checkpoint therapy has most impact in patients with pre-existing tumor-specific T cell responses (155), HPV16+ OPSCC patients received a combined treatment with ISA101 and nivolumab (146). ISA101 is an HPV16 -E6 and -E7-specific synthetic long peptide vaccine, which previously was shown to induce CR and PR in patients with HPV16-induced high-grade but premalignant disease $(166,167)$. The ORR of $33 \%$ and median OS of 17.5 months was regarded promising (146) when compared to PD-1 inhibition only in a similar patient group (143) or when compared to the study with durvalumab in which none of the $\mathrm{HPV}+$ patients responded (145). A randomized trial comparing the efficacy of $\mathrm{PD}-1$ blockade alone versus vaccination + PD-1 blockade is underway (Table 1). The outcome of the combination ISA101 and nivolumab trial argue for tumor-specific vaccination strategies. Approaches to stimulate the neoantigen repertoire are also warranted for the treatment of in particular HPV-negative OPSCC, similar to what has been done in other types of cancers (168-170).

Another option to stimulate tumor-reactive T cells might be through irradiation, as this has been shown to result in the release of antigens from tumor cells as well as in the induction of proinflammatory signals that trigger the innate immune system (171). Upon radiation, the tumor may serve as an in situ vaccine with the capacity to activate tumor-specific T cells. Spurred by the results with checkpoint blockade after radiation therapy in lung cancer (172), new trials are initiated in patients with HNSCC, including OPSCC (Table 1), using radiotherapy and checkpoint inhibition together or in combination with chemotherapy (173-175). The feasibility of using PD-L1 antibody avelumab with conventional cetuximab-radiotherapy as an alternative for advanced stage OPSCC patients unfit for cisplatin treatment was tested in a phase I study with 8 patients with OPSCC, 4 of which were HPV+. Immune toxicity was transient and manageable, and objective responses were observed in 4 of 6 evaluable OPSCC patients (3 complete responses and one partial response), including $3 \mathrm{HPV}+$ patients (176).

\section{PRECLINICAL DEVELOPMENTS}

There are several mouse models for HPV + HNSCC. Study of cell surface proteins expressed by MTEC tumors, made from mouse tonsillar epithelial cells that are transformed by HPV16 E6, E7, and hRAS, showed the expression of CD47 (177). By binding to signalregulatory protein alpha (SIRP-alpha) expressed on antigen processing cells, this transmembrane molecule blocks the phagocytosis and clearance of cells expressing CD47, resulting in 
the suppression of innate and adaptive anti-tumor responses. Targeting of CD47 using antibodies in rituximab-refractory nonHodgkin's lymphoma re-sensitized about $50 \%$ of these patients (178). The CD47-SIRP-alpha axis can also be targeted pharmacologically (179). The efficacy of radiation, which is a key component of the standard of care treatment for OPSCC, was shown to depend on intact $\mathrm{T}$ cell responses and was improved after CD47 knock-down in MTEC tumors (177), suggesting that CD47 may also play a key role in regulating immunity and as such the efficacy of standard of care treatment in OPSCC. Another study with mEER tumor cells, derived from the metastases of an HPV+ oropharyngeal murine cancer, injected into the flank of mice showed that the response to standard cisplatin-radiation therapy could be improved by adding cyclophosphamide and an inducible nitric oxide synthase (iNOS) inhibitor. Standard therapy did not alter the tumor microenvironment, which remained cold as indicated by high numbers of immune suppressive immune cells (MDSC, Tregs) and low numbers of T cells, M1 macrophages, and DCs (180). The addition of cyclophosphamide to the standard treatment converted treated tumors to hot but the combination with the iNOS inhibitor resulted in a strong influx of CD8+ and CD4+ Th1 cells as well as lead to durable control of established tumors (180). The use of cisplatin chemotherapy has been shown to increase tumor immune infiltration (181) and tumor cell killing by tumor necrosis factor alpha (TNF $\alpha$ )-producing T cells (182). The use of a low dose cisplatin was also shown to augment the effects of an adenovirus-based oncolytic virus therapy of subcutaneously injected mEER tumors. The effects of the oncolytic virus were clearly CD8+ T cell dependent and cisplatin was shown to augment the infiltration of the mEER tumors with HPV16 E7-specific CD8+ T cells (183). Interestingly, the anatomical location of the mEER tumors had a profound impact on the composition of the tumor infiltrating immune cells (184), quite reminiscent of what was observed in patients with HPV16-induced OPSCC and cervical cancer (24). Orthotopic injection of mEER tumor cells resulted in a much more inflamed tumor immune microenvironment, reflected by higher numbers of tumorinfiltrating CD8+ T cells and a stronger type 1 and 2 gene signature, than when these tumor cells were injected in the flank. Moreover, whereas the orthotopic growing mEER tumors were directly responsive to treatment with anti-PD-1 ( $>50 \%$ survival) and even better to the combination of anti-PD-1 and anti-CTLA-4 (> $90 \%$ survival), flank injected tumors did not show any response to PD-1 blockade alone whereas only $40 \%$ responded to the combination treatment. Intratumoral injections of STING agonist, to increase IFN signaling, resulted in a strong decrease of Tregs and MDSC and an almost complete eradication of flank tumors (184). The decrease of immune suppressive immune cells in flank-injected mEER tumors seems essential for a better outcome after both standard chemoradiation (180) and immunotherapy (184).

\section{PERSPECTIVES}

The use of 15 parameter flow cytometry, the development of over 30 marker panels by mass cytometry and the introduction of unbiased bioinformatical approaches to cluster cells based on the expression of all proteins assessed have led to a much better definition and quantification of the immune cell phenotypes that are present in OPSCC, solved debates on the prognostic role of certain subtypes and led to the identification of subtypes strongly associated with clinical outcome. The use of single cell RNA sequencing to study the transcriptome of intratumoral cells has provided new means to identify subtypes of immune cells and understand their functional properties as well as defined gene expression signatures with clinical outcome. In a first study of 26 patients with all types of HNSCC, including 7 OPSCC, the transcriptional signatures in helper CD4+ T cells and B cells were quite divergent between HPV-negative and HPV+ tumors, whereas that of CD8+ T cells and Tregs was quite similar (185). These results may not necessarily reflect a difference caused by HPV but can be caused by the different types of tumor and their location $(6,24,184)$. In a similar, but purely OPSCC and T cell focused transcriptome study, highly active tumor resident and tumor-reactive populations of $\mathrm{CD} 4+$ and $\mathrm{CD} 8+\mathrm{T}$ cells that displayed actionable checkpoints were found in OPSCC (45). Whilst these techniques give an unprecedented insight in the complexity of the immune infiltrate of tumors, they lack the spatial information on each cell. The fact that a fairly simple classification based on the distribution of $\mathrm{T}$ cells has a major impact on prognosis and response to immunotherapy stresses the importance of such analyses (27). Multispectral imaging using the Vectra not only allows for a more in-depth analyses of different types of immune cells within the same tumor section but also to study their interaction. The use of mass cytometry based imaging allows for many more markers to be studied in a spatial context (186) and one can foresee that this will bring a much deeper understanding on the types of cells in the TME as well as their interaction and how this affect clinical outcome.

The much better outcome of HPV+ OPSCC compared to their HPV-negative counterparts after standard of care therapy prompted discussions on de-intensified treatments, specifically with respect to the dose of cisplatin chemotherapy (15), but this led to inferior survival (17). It should be realized that the reason why patients with HPV+ tumors do better on this standard therapy is because of their extensive immune infiltration and this is enhanced by cisplatin (67, 180). Thus, rather than downscaling the use of chemotherapy one should consider to make optimal use of it. For instance, by taking advantage of the fact that chemotherapy may remove some of the immunosuppressive mechanisms that are at play in HPV-induced cancers $(187,188)$. Rational combination of the immunomodulatory properties of chemotherapy and radiation that turns up the heat in tumors are highly warranted. Based on a recent publication on therapeutic vaccination (189), it is unlikely that checkpoint therapy or ACT approaches will manage to do this. Potentially, oncolytic virus therapy may aid in this (NCT02626000).

Finally, checkpoint therapy has only limited effect in patients with head and neck cancer. One of the problems may be that these patients failed to or mounted only a weak response to tumor antigens. Whereas this can be achieved with therapeutic vaccines in patients with HPV+ tumors, this is more difficult when the tumor antigens are unknown, as is the case in HPVnegative OPSCC. To increase the number of tumor-reactive $\mathrm{T}$ 
cells, approaches are undertaken to either transfer TCR transgenic $\mathrm{T}$ cells into patients or by isolation and expansion of $\mathrm{T}$ cells which are most likely to be enriched for tumor-reactive $\mathrm{T}$ cells using the expression of the activation markers CD137, PD-1, or CD39 to select the T cells (190-193). These approaches have mostly targeted tumor-reactive CD8+ T cells, but in view of the important role (194-196) and efficacy of tumor-reactive CD4+ T cells (197-199) strategies to rapidly isolate that specific $\mathrm{T}$ cell fraction are needed. This may be achieved using the expression of CD39 on tumor-infiltrating CD4+ T cells (45).

\section{REFERENCES}

1. Shield KD, Ferlay J, Jemal A, Sankaranarayanan R, Chaturvedi AK, Bray F, et al. The global incidence of lip, oral cavity, and pharyngeal cancers by subsite in 2012. CA Cancer J Clin (2017) 67(1):51-64. doi: 10.3322/ caac. 21384

2. Torre LA, Bray F, Siegel RL, Ferlay J, Lortet-Tieulent J, Jemal A. Global cancer statistics, 2012. CA Cancer J Clin (2015) 65(2):87-108. doi: 10.3322/ caac. 21262

3. Mehanna H, Jones TM, Gregoire V, Ang KK. Oropharyngeal carcinoma related to human papillomavirus. BMJ (2010) 340:c1439. doi: 10.1136/ bmj.c1439

4. Brown LM, Check DP, Devesa SS. Oropharyngeal cancer incidence trends: diminishing racial disparities. Cancer Causes Control (2011) 22(5):753-63. doi: 10.1007/s10552-011-9748-1

5. van Monsjou HS, van Velthuysen ML, van den Brekel MW, Jordanova ES, Melief CJ, Balm AJ. Human papillomavirus status in young patients with head and neck squamous cell carcinoma. Int J Cancer (2012) 130(8):180612. doi: $10.1002 /$ ijc. 26195

6. Welters MJP, Ma W, Santegoets S, Goedemans R, Ehsan I, Jordanova ES, et al. Intratumoral HPV16-Specific T Cells Constitute a Type I-Oriented Tumor Microenvironment to Improve Survival in HPV16-Driven Oropharyngeal Cancer. Clin Cancer Res (2018) 24(3):634-47. doi: 10.1158/1078-0432.CCR-17-2140

7. Wang HF, Wang SS, Tang YJ, Chen Y, Zheng M, Tang YL, et al. The Double-Edged Sword-How Human Papillomaviruses Interact With Immunity in Head and Neck Cancer. Front Immunol (2019) 10:653. doi: 10.3389/fimmu.2019.00653

8. Syrjanen S, Syrjanen K. HPV in Head and Neck Carcinomas: Different HPV Profiles in Oropharyngeal Carcinomas - Why? Acta Cytol (2019) 63(2):12442. doi: 10.1159/000495727

9. Doorbar J, Quint W, Banks L, Bravo IG, Stoler M, Broker TR, et al. The biology and life-cycle of human papillomaviruses. Vaccine (2012) $30 \mathrm{Suppl}$ 5:F55-70. doi: 10.1016/j.vaccine.2012.06.083

10. Stanley M. Immunobiology of HPV and HPV vaccines. Gynecol Oncol (2008) 109(2 Suppl):S15-21. doi: 10.1016/j.ygyno.2008.02.003

11. Gupta S, Kumar P, Das BC. HPV: Molecular pathways and targets. Curr Probl Cancer (2018) 42(2):161-74. doi: 10.1016/j.currproblcancer.2018.03.003

12. zur Hausen H. Papillomaviruses and cancer: from basic studies to clinical application. Nat Rev Cancer (2002) 2(5):342-50. doi: 10.1038/nrc798

13. Ang KK, Harris J, Wheeler R, Weber R, Rosenthal DI, Nguyen-Tan PF, et al. Human papillomavirus and survival of patients with oropharyngeal cancer. N Engl J Med (2010) 363(1):24-35. doi: 10.1056/NEJMoa0912217

14. Wansom D, Light E, Worden F, Prince M, Urba S, Chepeha DB, et al. Correlation of cellular immunity with human papillomavirus 16 status and outcome in patients with advanced oropharyngeal cancer. Arch Otolaryngol Head Neck Surg (2010) 136(12):1267-73. doi: 10.1001/archoto.2010.211

15. Gillison ML, Trotti AM, Harris J, Eisbruch A, Harari PM, Adelstein DJ, et al. Radiotherapy plus cetuximab or cisplatin in human papillomavirus-positive oropharyngeal cancer (NRG Oncology RTOG 1016): a randomised, multicentre, non-inferiority trial. Lancet (2019) 393(10166):40-50. doi: 10.1016/S0140-6736(18)32779-X

16. Patel RR, Ludmir EB, Augustyn A, Zaorsky NG, Lehrer EJ, Ryali R, et al. Deintensification of therapy in human papillomavirus associated

\section{AUTHOR CONTRIBUTIONS}

The authors contributed equally to the review. All authors contributed to the article and approved the submitted version.

\section{FUNDING}

This study was financially supported by grants from the Dutch Cancer Society 2016-10726 to SB, MW, and SS.

oropharyngeal cancer: A systematic review of prospective trials. Oral Oncol (2020) 103:104608. doi: 10.1016/j.oraloncology.2020.104608

17. Ventz S, Trippa L, Schoenfeld JD. Lessons Learned from Deescalation Trials in Favorable Risk HPV-Associated Squamous Cell Head and Neck Cancer-A Perspective on Future Trial Designs. Clin Cancer Res (2019) 25(24):7281-6. doi: 10.1158/1078-0432.CCR-19-0945

18. Karim R, Tummers B, Meyers C, Biryukov JL, Alam S, Backendorf C, et al. Human papillomavirus (HPV) upregulates the cellular deubiquitinase UCHL1 to suppress the keratinocyte's innate immune response. PloS Pathog (2013) 9(5):e1003384. doi: 10.1371/journal.ppat.1003384

19. Ma W, Melief CJ, van der Burg SH. Control of immune escaped human papilloma virus is regained after therapeutic vaccination. Curr Opin Virol (2017) 23:16-22. doi: 10.1016/j.coviro.2017.02.005

20. Tummers B, et Goedemans R, Pelascini LP, Jordanova ES, van Esch EM, Meyers $C$, et al. The interferon-related developmental regulator 1 is used by human papillomavirus to suppress NFkappaB activation. Nat Commun (2015) 6:6537. doi: 10.1038/ncomms7537

21. Steinbach $A$, Riemer $A B$. Immune evasion mechanisms of human papillomavirus: An update. Int J Cancer (2018) 142(2):224-9. doi: $10.1002 / \mathrm{ijc} .31027$

22. Zhou C, Tuong ZK, Frazer IH. Papillomavirus Immune Evasion Strategies Target the Infected Cell and the Local Immune System. Front Oncol (2019) 9:682. doi: $10.3389 /$ fonc. 2019.00682

23. Matlung SE, Wilhelmina van Kempen PM, Bovenschen N, van Baarle D, Willems SM. Differences in T-cell infiltrates and survival between HPV+ and HPV- oropharyngeal squamous cell carcinoma. Future Sci OA (2016) 2(1): FSO88. doi: 10.4155/fso.15.88

24. Santegoets SJ, van Ham VJ, Ehsan I, Charoentong P, Duurland CL, van Unen V, et al. The Anatomical Location Shapes the Immune Infiltrate in Tumors of Same Etiology and Affects Survival. Clin Cancer Res (2019) 25 (1):240-52. doi: 10.1158/1078-0432.CCR-18-1749

25. Fridman WH, Galon J, Dieu-Nosjean MC, Cremer I, Fisson S, Damotte D, et al. Immune infiltration in human cancer: prognostic significance and disease control. Curr Top Microbiol Immunol (2011) 344:1-24. doi: 10.1007/ 82_2010_46

26. Wallis SP, Stafford ND, Greenman J. Clinical relevance of immune parameters in the tumor microenvironment of head and neck cancers. Head Neck (2015) 37(3):449-59. doi: 10.1002/hed.23736

27. Galon J, Bruni D. Approaches to treat immune hot, altered and cold tumours with combination immunotherapies. Nat Rev Drug Discovery (2019) 18 (3):197-218. doi: 10.1038/s41573-018-0007-y

28. Van Abel KM, Routman DM, Moore EJ, Ma DJ, Yin LX, Fields PA, et al. T cell fraction impacts oncologic outcomes in human papillomavirus associated oropharyngeal squamous cell carcinoma. Oral Oncol (2020) 111:104894. doi: 10.1016/j.oraloncology.2020.104894

29. Gillison ML, Blumenschein GJr., Fayette J, Guigay J, Colevas AD, Licitra L, et al CheckMate 141: 1-Year Update and Subgroup Analysis of Nivolumab as FirstLine Therapy in Patients with Recurrent/Metastatic Head and Neck Cancer. Oncologist (2018) 23(9):1079-82. doi: 10.1634/theoncologist.2017-0674

30. Giraldo NA, Sanchez-Salas R, Peske JD, Vano Y, Becht E, Petitprez F, et al. The clinical role of the TME in solid cancer. Br J Cancer (2019) 120(1):4553. doi: 10.1038/s41416-018-0327-z

31. Jung AC, Guihard S, Krugell S, Ledrappier S, Brochot A, Dalstein V, et al. CD8-alpha T-cell infiltration in human papillomavirus-related 
oropharyngeal carcinoma correlates with improved patient prognosis. Int $J$ Cancer (2013) 132(2):E26-36. doi: 10.1002/ijc.27776

32. Ward MJ, Thirdborough SM, Mellows T, Riley C, Harris S, Suchak K, et al. Tumour-infiltrating lymphocytes predict for outcome in HPV-positive oropharyngeal cancer. Br J Cancer (2014) 110(2):489-500. doi: 10.1038/ bjc. 2013.639

33. Gurin D, Slavik M, Hermanova M, Selingerova I, Kazda T, Hendrych M, et al. The tumor immune microenvironment and its implications for clinical outcome in patients with oropharyngeal squamous cell carcinoma. J Oral Pathol Med (2020) 49(9):886-96. doi: 10.1111/jop.13055

34. Wansom D, Light E, Thomas D, Worden F, Prince M, Urba S, et al. Infiltrating lymphocytes and human papillomavirus-16-associated oropharyngeal cancer. Laryngoscope (2012) 122(1):121-7. doi: 10.1002/ lary.22133

35. Lee YS, Park JY, Cho KJ, Kim SB, Lee SW, Choi SH, et al. Composition of inflammatory cells regulating the response to concurrent chemoradiation therapy for HPV (+) tonsil cancer. Oral Oncol (2015) 51(12):1113-9. doi: 10.1016/j.oraloncology.2015.10.001

36. Poropatich K, Hernandez D, Fontanarosa J, Brown K, Woloschak G, Paintal A, et al. Peritumoral cuffing by T-cell tumor-infiltrating lymphocytes distinguishes HPV-related oropharyngeal squamous cell carcinoma from oral cavity squamous cell carcinoma. J Oral Pathol Med (2017) 46(10):972-8. doi: 10.1111 /jop. 12605

37. Nordfors C, Grun N, Tertipis N, Ahrlund-Richter A, Haeggblom L, Sivars L, et al. CD8+ and CD4+ tumour infiltrating lymphocytes in relation to human papillomavirus status and clinical outcome in tonsillar and base of tongue squamous cell carcinoma. Eur J Cancer (2013) 49(11):2522-30. doi: 10.1016/ j.ejca.2013.03.019

38. Punt S, Dronkers EA, Welters MJ, Goedemans R, Koljenovic S, Bloemena E, et al. A beneficial tumor microenvironment in oropharyngeal squamous cell carcinoma is characterized by a high T cell and low IL-17(+) cell frequency. Cancer Immunol Immunother (2016) 65(4):393-403. doi: 10.1007/s00262016-1805-x

39. Lin CM, Lin LW, Chen YW, Ye YL. The expression and prognostic impact of proinflammatory cytokines and their associations with carcinogens in oropharyngeal squamous cell carcinoma. Cancer Immunol Immunother (2020) 69(4):549-58. doi: 10.1007/s00262-020-02488-w

40. Partlova S, Boucek J, Kloudova K, Lukesova E, Zabrodsky M, Grega M, et al. Distinct patterns of intratumoral immune cell infiltrates in patients with $\mathrm{HPV}$-associated compared to non-virally induced head and neck squamous cell carcinoma. Oncoimmunology (2015) 4(1):e965570. doi: 10.4161/ 21624011.2014.965570

41. Solomon B, Young RJ, Bressel M, Cernelc J, Savas P, Liu H, et al. Identification of an excellent prognosis subset of human papillomavirusassociated oropharyngeal cancer patients by quantification of intratumoral CD103(+) immune cell abundance. Ann Oncol (2019) 30(10):1638-46. doi: 10.1093/annonc/mdz271

42. Hewavisenti R, Ferguson A, Wang K, Jones D, Gebhardt T, Edwards J, et al. CD103+ tumor-resident CD8+ T cell numbers underlie improved patient survival in oropharyngeal squamous cell carcinoma. J Immunother Cancer (2020) 8(1):e000452. doi: 10.1136/jitc-2019-000452

43. Mueller SN, Mackay LK. Tissue-resident memory T cells: local specialists in immune defence. Nat Rev Immunol (2016) 16(2):79-89. doi: 10.1038/nri.2015.3

44. Savas P, Virassamy B, Ye C, Salim A, Mintoff CP, Caramia F, et al. Single-cell profiling of breast cancer $\mathrm{T}$ cells reveals a tissue-resident memory subset associated with improved prognosis. Nat Med (2018) 24(7):986-93. doi: 10.1038/s41591-018-0078-7

45. Kortekaas KE, Santegoets SJ, Sturm G, Ehsan I, van Egmond SL, Finotello F, et al. CD39 identifies the CD4+ tumor-specific $\mathrm{T}$ cell population in human cancer. Cancer Immunol Res (2020) 8(10):1311-21. doi: 10.1158/23266066.CIR-20-0270

46. Cioni B, Jordanova ES, Hooijberg E, van der Linden R, de Menezes RX, Tan $\mathrm{K}$, et al. HLA class II expression on tumor cells and low numbers of tumorassociated macrophages predict clinical outcome in oropharyngeal cancer. Head Neck (2019) 41(2):463-78. doi: 10.1002/hed.25442

47. Ou D, Adam J, Garberis I, Blanchard P, Nguyen F, Levy A, et al. Influence of tumor-associated macrophages and HLA class I expression according to HPV status in head and neck cancer patients receiving chemo/ bioradiotherapy. Radiother Oncol (2019) 130:89-96. doi: 10.1016/ j.radonc.2018.08.013

48. Reeves E, Wood O, Ottensmeier CH, King EV, Thomas GJ, Elliott T, et al. HPV Epitope Processing Differences Correlate with ERAP1 Allotype and Extent of CD8(+) T-cell Tumor Infiltration in OPSCC. Cancer Immunol Res (2019) 7(7):1202-13. doi: 10.1158/2326-6066.CIR-18-0498

49. Näsman A, Andersson E, Marklund L, Tertipis N, Hammarstedt-Nordenvall L, Attner P, et al. HLA class I and II expression in oropharyngeal squamous cell carcinoma in relation to tumor HPV status and clinical outcome. PloS One (2013) 8(10):e77025. doi: 10.1371/journal.pone.0077025

50. Näsman A, Andersson E, Nordfors C, Grun N, Johansson H, MunckWikland E, et al. MHC class I expression in HPV positive and negative tonsillar squamous cell carcinoma in correlation to clinical outcome. Int $J$ Cancer (2013) 132(1):72-81. doi: 10.1002/ijc.27635

51. O'Higgins C, Ward FJ, Abu Eid R. Deciphering the Role of Regulatory CD4 T Cells in Oral and Oropharyngeal Cancer: A Systematic Review. Front Oncol (2018) 8:442. doi: 10.3389/fonc.2018.00442

52. Drennan S, Stafford ND, Greenman J, Green VL. Increased frequency and suppressive activity of $\mathrm{CD} 127$ (low/-) regulatory $\mathrm{T}$ cells in the peripheral circulation of patients with head and neck squamous cell carcinoma are associated with advanced stage and nodal involvement. Immunology (2013) 140(3):335-43. doi: 10.1111/imm.12144

53. Sun W, Li WJ, Wu CY, Zhong H, Wen WP. CD45RA-Foxp3high but not CD45RA+Foxp3low suppressive $T$ regulatory cells increased in the peripheral circulation of patients with head and neck squamous cell carcinoma and correlated with tumor progression. J Exp Clin Cancer Res (2014) 33:35. doi: 10.1186/1756-9966-33-35

54. Distel LV, Fickenscher R, Dietel K, Hung A, Iro H, Zenk J, et al. Tumour infiltrating lymphocytes in squamous cell carcinoma of the oro- and hypopharynx: prognostic impact may depend on type of treatment and stage of disease. Oral Oncol (2009) 45(10):e167-74. doi: 10.1016/ j.oraloncology.2009.05.640

55. Bron L, Jandus C, Andrejevic-Blant S, Speiser DE, Monnier P, Romero P, et al. Prognostic value of arginase-II expression and regulatory T-cell infiltration in head and neck squamous cell carcinoma. Int $J$ Cancer (2013) 132(3):E85-93. doi: 10.1002/ijc.27728

56. Lukesova E, Boucek J, Rotnaglova E, Salakova M, Koslabova E, Grega M, et al. High level of Tregs is a positive prognostic marker in patients with HPV-positive oral and oropharyngeal squamous cell carcinomas. BioMed Res Int (2014) 2014:303929. doi: 10.1155/2014/303929

57. deLeeuw RJ, Kost SE, Kakal JA, Nelson BH. The prognostic value of FoxP3+ tumor-infiltrating lymphocytes in cancer: a critical review of the literature. Clin Cancer (2012) 18(11):3022-9. doi: 10.1158/1078-0432.CCR-11-3216

58. Salama P, Phillips M, Grieu F, Morris M, Zeps N, Joseph D, et al. Tumorinfiltrating FOXP3 $+\mathrm{T}$ regulatory cells show strong prognostic significance in colorectal cancer. J Clin Oncol (2009) 27(2):186-92. doi: 10.1200/ JCO.2008.18.7229

59. Miyara M, Yoshioka Y, Kitoh A, Shima T, Wing K, Niwa A, et al. Functional delineation and differentiation dynamics of human CD4+ T cells expressing the FoxP3 transcription factor. Immunity (2009) 30(6):899-911. doi: 10.1016/j.immuni.2009.03.019

60. Saito T, Nishikawa H, Wada H, Nagano Y, Sugiyama D, Atarashi K, et al. Two FOXP3(+)CD4(+) T cell subpopulations distinctly control the prognosis of colorectal cancers. Nat Med (2016) 22(6):679-84. doi: 10.1038/nm.4086

61. Sugiyama D, Nishikawa H, Maeda Y, Nishioka M, Tanemura A, Katayama I, et al. Anti-CCR4 $\mathrm{mAb}$ selectively depletes effector-type FoxP3+CD4+ regulatory $\mathrm{T}$ cells, evoking antitumor immune responses in humans. Proc Natl Acad Sci USA (2013) 110(44):17945-50. doi: 10.1073/pnas.1316796110

62. Badoual C, Hans S, Merillon N, Van Ryswick C, Ravel P, Benhamouda N, et al. PD-1-expressing tumor-infiltrating $\mathrm{T}$ cells are a favorable prognostic biomarker in HPV-associated head and neck cancer. Cancer Res (2013) 73 (1):128-38. doi: 10.1158/0008-5472.CAN-12-2606

63. Chaudhry A, Rudra D, Treuting P, Samstein RM, Liang Y, Kas A, et al. CD4+ regulatory T cells control TH17 responses in a Stat3-dependent manner. Science (2009) 326(5955):986-91. doi: 10.1126/science.1172702

64. Koch MA, Tucker-Heard G, Perdue NR, Killebrew JR, Urdahl KB, Campbell DJ. The transcription factor T-bet controls regulatory $\mathrm{T}$ cell homeostasis and 
function during type 1 inflammation. Nat Immunol (2009) 10(6):595-602. doi: 10.1038/ni.1731

65. Wang Y, Su MA, Wan YY. An essential role of the transcription factor GATA-3 for the function of regulatory T cells. Immunity (2011) 35(3):33748. doi: 10.1016/j.immuni.2011.08.012

66. Zheng Y, Chaudhry A, Kas A, deRoos P, Kim JM, Chu TT, et al. Regulatory T-cell suppressor program co-opts transcription factor IRF4 to control T(H) 2 responses. Nature (2009) 458(7236):351-6. doi: 10.1038/nature07674

67. Santegoets SJ, Duurland CL, Jordanova ES, van Ham JJ, Ehsan I, van Egmond SL, et al. Tbet-positive regulatory $\mathrm{T}$ cells accumulate in oropharyngeal cancers with ongoing tumor-specific type $1 \mathrm{~T}$ cell responses. J Immunother Cancer (2019) 7 (1):14. doi: 10.1186/s40425-019-0497-0

68. Mantovani A, Marchesi F, Malesci A, Laghi L, Allavena P. Tumourassociated macrophages as treatment targets in oncology. Nat Rev Clin Oncol (2017) 14(7):399-416. doi: 10.1038/nrclinonc.2016.217

69. Nakamura K, Smyth MJ. Myeloid immunosuppression and immune checkpoints in the tumor microenvironment. Cell Mol Immunol (2020) 17 (1):1-12. doi: 10.1038/s41423-019-0306-1

70. Locati M, Curtale G, Mantovani A. Diversity, Mechanisms, and Significance of Macrophage Plasticity. Annu Rev Pathol (2020) 15:123-47. doi: 10.1146/ annurev-pathmechdis-012418-012718

71. Biswas SK, Mantovani A. Macrophage plasticity and interaction with lymphocyte subsets: cancer as a paradigm. Nat Immunol (2010) 11 (10):889-96. doi: 10.1038/ni.1937

72. Anfray C, Ummarino A, Andon FT, Allavena P. Current Strategies to Target Tumor-Associated-Macrophages to Improve Anti-Tumor Immune Responses. Cells (2019) 9(1):46. doi: 10.3390/cells9010046

73. Heusinkveld M, de Vos van Steenwijk PJ, Goedemans R, Ramwadhdoebe $\mathrm{TH}$, Gorter A, Welters MJ, et al. M2 macrophages induced by prostaglandin E2 and IL-6 from cervical carcinoma are switched to activated M1 macrophages by CD4+ Th1 cells. J Immunol (2011) 187(3):1157-65. doi: 10.4049/jimmunol.1100889

74. Santegoets SJ, Duurland CL, Jordanova EJ, van Ham VJ, Ehsan I, Loof NM, et al. CD163(+) cytokine-producing CDC2 stimulate intratumoral type $1 \mathrm{~T}$ cell responses in HPV16-induced oropharyngeal cancer. J Immunother Cancer (2020) 8(2):e001053. doi: 10.1136/jitc-2020-001053

75. Balermpas P, Rodel F, Liberz R, Oppermann J, Wagenblast J, Ghanaati S, et al. Head and neck cancer relapse after chemoradiotherapy correlates with CD163+ macrophages in primary tumour and CD11b+ myeloid cells in recurrences. Br J Cancer (2014) 111(8):1509-18. doi: 10.1038/bjc.2014.446

76. de Vos van Steenwijk PJ, Ramwadhdoebe TH, Goedemans R, Doorduijn EM, van Ham JJ, Gorter A, et al. Tumor-infiltrating CD14-positive myeloid cells and CD8-positive T-cells prolong survival in patients with cervical carcinoma. Int J Cancer (2013) 133(12):2884-94. doi: 10.1002/ijc.28309

77. Heusinkveld M, van der Burg SH. Identification and manipulation of tumor associated macrophages in human cancers. J Transl Med (2011) 9:216. doi: 10.1186/1479-5876-9-216

78. Etzerodt A, Tsalkitzi K, Maniecki M, Damsky W, Delfini M, Baudoin E, et al. Specific targeting of $\mathrm{CD} 163(+)$ TAMs mobilizes inflammatory monocytes and promotes T cell-mediated tumor regression. J Exp Med (2019) 216 (10):2394-411. doi: 10.1084/jem.20182124

79. van der Sluis TC, Sluijter M, van Duikeren S, West BL, Melief CJ, Arens R, et al. Therapeutic Peptide Vaccine-Induced CD8 T Cells Strongly Modulate Intratumoral Macrophages Required for Tumor Regression. Cancer Immunol Res (2015) 3(9):1042-51. doi: 10.1158/2326-6066.CIR-15-0052

80. Jahchan NS, Mujal AM, Pollack JL, Binnewies M, Sriram V, Reyno L, et al. Tuning the Tumor Myeloid Microenvironment to Fight Cancer. Front Immunol (2019) 10:1611. doi: 10.3389/fimmu.2019.01611

81. Mandruzzato S, Brandau S, Britten CM, Bronte V, Damuzzo V, Gouttefangeas C, et al. Toward harmonized phenotyping of human myeloid-derived suppressor cells by flow cytometry: results from an interim study. Cancer Immunol Immunother (2016) 65(2):161-9. doi: 10.1007/s00262-015-1782-5

82. Cassetta L, Baekkevold ES, Brandau S, Bujko A, Cassatella MA, Dorhoi A, et al. Deciphering myeloid-derived suppressor cells: isolation and markers in humans, mice and non-human primates. Cancer Immunol Immunother (2019) 68(4):687-97. doi: 10.1007/s00262-019-02302-2

83. Lang S, Bruderek K, Kaspar C, Hoing B, Kanaan O, Dominas N, et al. Clinical Relevance and Suppressive Capacity of Human Myeloid-Derived
Suppressor Cell Subsets. Clin Cancer Res (2018) 24(19):4834-44. doi: 10.1158/1078-0432.CCR-17-3726

84. Califano JA, Khan Z, Noonan KA, Rudraraju L, Zhang Z, Wang H, et al. Tadalafil augments tumor specific immunity in patients with head and neck squamous cell carcinoma. Clin Cancer Res (2015) 21(1):30-8. doi: 10.1158/ 1078-0432.CCR-14-1716

85. Davis RJ, Van Waes C, Allen CT. Overcoming barriers to effective immunotherapy: MDSCs, TAMs, and Tregs as mediators of the immunosuppressive microenvironment in head and neck cancer. Oral Oncol (2016) 58:59-70. doi: 10.1016/j.oraloncology.2016.05.002

86. Dutertre CA, Becht E, Irac SE, Khalilnezhad A, Narang V, Khalilnezhad S, et al. Single-Cell Analysis of Human Mononuclear Phagocytes Reveals Subset-Defining Markers and Identifies Circulating Inflammatory Dendritic Cells. Immunity (2019) 51(3):573-89.e578. doi: 10.1016/ j.immuni.2019.08.008

87. Villani AC, Satija R, Reynolds G, Sarkizova S, Shekhar K, Fletcher J, et al. Single-cell RNA-seq reveals new types of human blood dendritic cells, monocytes, and progenitors. Science (2017) 356(6335):eaah4573. doi: 10.1126/science.aah4573

88. Bourdely P, Anselmi G, Vaivode K, Ramos RN, Missolo-Koussou Y, Hidalgo S, et al. Transcriptional and Functional Analysis of $\mathrm{CD} 1 \mathrm{c}(+)$ Human Dendritic Cells Identifies a CD163(+) Subset Priming CD8(+)CD103(+) T Cells. Immunity (2020) 53(2):335-52.e8. doi: 10.1016/j.immuni.2020.06.002

89. De Meulenaere A, Vermassen T, Aspeslagh S, Deron P, Duprez F, Laukens D, et al. Tumor PD-L1 status and CD8(+) tumor-infiltrating T cells: markers of improved prognosis in oropharyngeal cancer. Oncotarget (2017) 8 (46):80443-52. doi: 10.18632/oncotarget.19045

90. Fukushima Y, Someya M, Nakata K, Hori M, Kitagawa M, Hasegawa T, et al. Influence of PD-L1 expression in immune cells on the response to radiation therapy in patients with oropharyngeal squamous cell carcinoma. Radiother Oncol (2018) 129(2):409-14. doi: 10.1016/j.radonc.2018.08.023

91. Lecerf C, Kamal M, Vacher S, Chemlali W, Schnitzler A, Morel C, et al. Immune gene expression in head and neck squamous cell carcinoma patients. Eur J Cancer (2019) 121:210-23. doi: 10.1016/j.ejca. 2019.08.028

92. Sato F, Ono T, Kawahara A, Kawaguchi T, Tanaka H, Shimamatsu K, et al. Prognostic impact of p16 and PD-L1 expression in patients with oropharyngeal squamous cell carcinoma receiving a definitive treatment. J Clin Pathol (2019) 72(8):542-9. doi: 10.1136/jclinpath-2019-205818

93. Young RJ, Bressel M, Porceddu S, Cernelc J, Savas P, Liu H, et al. Validation and characterisation of prognostically significant PD-L1(+) immune cells in HPV+ oropharyngeal squamous cell carcinoma. Oral Oncol (2020) 101:104516. doi: 10.1016/j.oraloncology.2019.104516

94. Kim MH, Kim JH, Lee JM, Choi JW, Jung D, Cho H, et al. Molecular subtypes of oropharyngeal cancer show distinct immune microenvironment related with immune checkpoint blockade response. Br J Cancer (2020) 122 (11):1649-60. doi: 10.1038/s41416-020-0796-8

95. Oguejiofor K, Galletta-Williams H, Dovedi SJ, Roberts DL, Stern PL, West CM. Distinct patterns of infiltrating CD8 $+\mathrm{T}$ cells in HPV+ and CD68 macrophages in HPV- oropharyngeal squamous cell carcinomas are associated with better clinical outcome but PD-L1 expression is not prognostic. Oncotarget (2017) 8(9):14416-27. doi: 10.18632/ oncotarget.14796

96. Andre P, Denis C, Soulas C, Bourbon-Caillet C, Lopez J, Arnoux T, et al. Anti-NKG2A mAb Is a Checkpoint Inhibitor that Promotes Anti-tumor Immunity by Unleashing Both T and NK Cells. Cell (2018) 175(7):173143.e1713. doi: 10.1016/j.cell.2018.10.014

97. van Montfoort N, Borst L, Korrer MJ, Sluijter M, Marijt KA, Santegoets SJ, et al. NKG2A Blockade Potentiates CD8 T Cell Immunity Induced by Cancer Vaccines. Cell (2018) 175(7):1744-55.e1715. doi: 10.1016/ j.cell.2018.10.028

98. Gooden M, Lampen M, Jordanova ES, Leffers N, Trimbos JB, van der Burg $\mathrm{SH}$, et al. HLA-E expression by gynecological cancers restrains tumorinfiltrating CD8(+) T lymphocytes. Proc Natl Acad Sci USA (2011) 108 (26):10656-61. doi: 10.1073/pnas.1100354108

99. Talebian Yazdi M, van Riet S, van Schadewijk A, Fiocco M, van Hall T, Taube $\mathrm{C}$, et al. The positive prognostic effect of stromal CD8+ tumorinfiltrating $\mathrm{T}$ cells is restrained by the expression of HLA-E in non-small cell 
lung carcinoma. Oncotarget (2016) 7(3):3477-88. doi: 10.18632/ oncotarget. 6506

100. van Hall T, Andre P, Horowitz A, Ruan DF, Borst L, Zerbib R, et al. Monalizumab: inhibiting the novel immune checkpoint NKG2A. J Immunother Cancer (2019) 7(1):263. doi: 10.1186/s40425-019-0761-3

101. Gameiro SF, Ghasemi F, Barrett JW, Koropatnick J, Nichols AC, Mymryk JS, et al. Treatment-naive HPV+ head and neck cancers display a T-cellinflamed phenotype distinct from their HPV- counterparts that has implications for immunotherapy. Oncoimmunology (2018) 7(10):e1498439. doi: 10.1080/2162402X.2018.1498439

102. Huang SH, Waldron JN, Milosevic M, Shen X, Ringash J, Su J, et al. Prognostic value of pretreatment circulating neutrophils, monocytes, and lymphocytes in oropharyngeal cancer stratified by human papillomavirus status. Cancer (2015) 121(4):545-55. doi: 10.1002/cncr.29100

103. Panje C, Riesterer O, Glanzmann C, Studer G. Neutrophil-lymphocyte ratio complements volumetric staging as prognostic factor in patients treated with definitive radiotherapy for oropharyngeal cancer. BMC Cancer (2017) 17 (1):643. doi: 10.1186/s12885-017-3590-0

104. So YK, Lee G, Oh D, Byeon S, Park W, Chung MK. Prognostic Role of Neutrophil-to-Lymphocyte Ratio in Patients with Human PapillomavirusPositive Oropharyngeal Cancer. Otolaryngol Head Neck Surg (2018) 159 (2):303-9. doi: 10.1177/0194599818764651

105. Sumner WA, Stokes WA, Oweida A, Berggren KL, McDermott JD, Raben D, et al. Survival impact of pre-treatment neutrophils on oropharyngeal and laryngeal cancer patients undergoing definitive radiotherapy. J Transl Med (2017) 15(1):168. doi: 10.1186/s12967-017-1268-7

106. Trellakis S, Farjah H, Bruderek K, Dumitru CA, Hoffmann TK, Lang S, et al. Peripheral blood neutrophil granulocytes from patients with head and neck squamous cell carcinoma functionally differ from their counterparts in healthy donors. Int J Immunopathol Pharmacol (2011) 24(3):683-93. doi: 10.1177/039463201102400314

107. Takahashi H, Sakakura K, Tada H, Kaira K, Oyama T, Chikamatsu K. Prognostic significance and population dynamics of peripheral monocytes in patients with oropharyngeal squamous cell carcinoma. Head Neck (2019) 41 (6):1880-8. doi: 10.1002/hed.25625

108. Santegoets S, de Groot AF, Dijkgraaf EM, Simoes AMC, van der Noord VE, van Ham JJ, et al. The blood mMDSC to DC ratio is a sensitive and easy to assess independent predictive factor for epithelial ovarian cancer survival. Oncoimmunology (2018) 7(8):e1465166. doi: 10.1080/2162402X.2018.1465166

109. Kano S, Homma A, Hatakeyama H, Mizumachi T, Sakashita T, Kakizaki T, et al. Pretreatment lymphocyte-to-monocyte ratio as an independent prognostic factor for head and neck cancer. Head Neck (2017) 39(2):24753. doi: 10.1002/hed.24576

110. Heusinkveld M, Goedemans R, Briet RJ, Gelderblom H, Nortier JW, Gorter A, et al. Systemic and local human papillomavirus 16-specific T-cell immunity in patients with head and neck cancer. Int J Cancer (2012) 131 (2):E74-85. doi: 10.1002/ijc.26497

111. Masterson L, Lechner M, Loewenbein S, Mohammed H, Davies-Husband C, Fenton T, et al. CD8(+) T cell response to human papillomavirus $16 \mathrm{E} 7$ is able to predict survival outcome in oropharyngeal cancer. Eur J Cancer (2016) 67:141-51. doi: 10.1016/j.ejca.2016.08.012

112. Bhatt KH, Neller MA, Srihari S, Crooks P, Lekieffre L, Aftab BT, et al. Profiling HPV-16-specific T cell responses reveals broad antigen reactivities in oropharyngeal cancer patients. J Exp Med (2020) 217(10):e20200389. doi: 10.1084/jem.20200389

113. de Jong A, van der Burg SH, Kwappenberg KM, van der Hulst JM, Franken KL, Geluk A, et al. Frequent detection of human papillomavirus 16 E2-specific Thelper immunity in healthy subjects. Cancer Res (2002) 62(2):472-9.

114. de Jong A, van Poelgeest MI, van der Hulst JM, Drijfhout JW, Fleuren GJ, Melief CJ, et al. Human papillomavirus type 16-positive cervical cancer is associated with impaired CD4+ T-cell immunity against early antigens E2 and E6. Cancer Res (2004) 64(15):5449-55. doi: 10.1158/0008-5472.CAN04-0831

115. Welters MJ, de Jong A, van den Eeden SJ, van der Hulst JM, Kwappenberg KM, Hassane S, et al. Frequent display of human papillomavirus type 16 E6specific memory t-Helper cells in the healthy population as witness of previous viral encounter. Cancer Res (2003) 63(3):636-41.
116. Angell H, Galon J. From the immune contexture to the Immunoscore: the role of prognostic and predictive immune markers in cancer. Curr Opin Immunol (2013) 25(2):261-7. doi: 10.1016/j.coi.2013.03.004

117. Licitra L, Perrone F, Bossi P, Suardi S, Mariani L, Artusi R, et al. High-risk human papillomavirus affects prognosis in patients with surgically treated oropharyngeal squamous cell carcinoma. J Clin Oncol (2006) 24(36):5630-6. doi: 10.1200/JCO.2005.04.6136

118. Thurlow JK, Pena Murillo CL, Hunter KD, Buffa FM, Patiar S, Betts G, et al. Spectral clustering of microarray data elucidates the roles of microenvironment remodeling and immune responses in survival of head and neck squamous cell carcinoma. J Clin Oncol (2010) 28(17):2881-8. doi: 10.1200/JCO.2009.24.8724

119. Al-Taei S, Banner R, Powell N, Evans M, Palaniappan N, Tabi Z, et al. Decreased HPV-specific $T$ cell responses and accumulation of immunosuppressive influences in oropharyngeal cancer patients following radical therapy. Cancer Immunol Immunother (2013) 62(12):1821-30. doi: 10.1007/s00262-013-1488-5

120. Hladikova K, Partlova S, Koucky V, Boucek J, Fonteneau JF, Zabrodsky M, et al. Dysfunction of HPV16-specific CD8+ T cells derived from oropharyngeal tumors is related to the expression of Tim-3 but not PD-1. Oral Oncol (2018) 82:75-82. doi: 10.1016/j.oraloncology.2018.05.010

121. Parikh F, Duluc D, Imai N, Clark A, Misiukiewicz K, Bonomi M, et al. Chemoradiotherapy-induced upregulation of PD-1 antagonizes immunity to HPV-related oropharyngeal cancer. Cancer Res (2014) 74(24):7205-16. doi: 10.1158/0008-5472.CAN-14-1913

122. Ramos CA, Narala N, Vyas GM, Leen AM, Gerdemann U, Sturgis EM, et al. Human papillomavirus type 16 E6/E7-specific cytotoxic T lymphocytes for adoptive immunotherapy of HPV-associated malignancies. J Immunother (2013) 36(1):66-76. doi: 10.1097/CJI.0b013e318279652e

123. Smith EM, Pawlita M, Rubenstein LM, Haugen TH, Hamsikova E, Turek LP. Risk factors and survival by HPV-16 E6 and E7 antibody status in human papillomavirus positive head and neck cancer. Int J Cancer (2010) 127 (1):111-7. doi: 10.1002/ijc.25015

124. Nasman A, Romanitan M, Nordfors C, Grun N, Johansson H, Hammarstedt $\mathrm{L}$, et al. Tumor infiltrating CD8+ and Foxp3+ lymphocytes correlate to clinical outcome and human papillomavirus (HPV) status in tonsillar cancer. PloS One (2012) 7(6):e38711. doi: 10.1371/journal.pone.0038711

125. Brown SD, Warren RL, Gibb EA, Martin SD, Spinelli JJ, Nelson BH, et al. Neo-antigens predicted by tumor genome meta-analysis correlate with increased patient survival. Genome Res (2014) 24(5):743-50. doi: 10.1101/ gr.165985.113

126. Stransky N, Egloff AM, Tward AD, Kostic AD, Cibulskis K, Sivachenko A, et al. The mutational landscape of head and neck squamous cell carcinoma. Science (2011) 333(6046):1157-60. doi: 10.1126/science.1208130

127. Ren L, Leisegang M, Deng B, Matsuda T, Kiyotani K, Kato T, et al. Identification of neoantigen-specific $\mathrm{T}$ cells and their targets: implications for immunotherapy of head and neck squamous cell carcinoma. Oncoimmunology (2019) 8(4): e1568813. doi: 10.1080/2162402X.2019.1568813

128. Yang W, Lee KW, Srivastava RM, Kuo F, Krishna C, Chowell D, et al. Immunogenic neoantigens derived from gene fusions stimulate $\mathrm{T}$ cell responses. Nat Med (2019) 25(5):767-75. doi: 10.1038/s41591-019-0434-2

129. van den Bulk J, Verdegaal EME, Ruano D, Ijsselsteijn ME, Visser M, van der Breggen R, et al. Neoantigen-specific immunity in low mutation burden colorectal cancers of the consensus molecular subtype 4. Genome Med (2019) 11(1):87. doi: 10.1186/s13073-019-0697-8

130. De Stefani A, Forni G, Ragona R, Cavallo G, Bussi M, Usai A, et al. Improved survival with perilymphatic interleukin 2 in patients with resectable squamous cell carcinoma of the oral cavity and oropharynx. Cancer (2002) 95(1):90-7. doi: 10.1002/cncr.10654

131. van Poelgeest MI, Visconti VV, Aghai Z, van Ham VJ, Heusinkveld M, Zandvliet ML, et al. Potential use of lymph node-derived HPV-specific T cells for adoptive cell therapy of cervical cancer. Cancer Immunol Immunother (2016) 65(12):1451-63. doi: 10.1007/s00262-016-1892-8

132. Wolf GT, Ee WEJr., Dolan RW, Moyer JS, Kaplan MJ, Spring PM, et al. Novel neoadjuvant immunotherapy regimen safety and survival in head and neck squamous cell cancer. Head Neck (2011) 33(12):1666-74. doi: 10.1002/ hed. 21660 
133. Berinstein NL, Wolf GT, Naylor PH, Baltzer L, Egan JE, Brandwein HJ, et al. Increased lymphocyte infiltration in patients with head and neck cancer treated with the IRX-2 immunotherapy regimen. Cancer Immunol Immunother (2012) 61(6):771-82. doi: 10.1007/s00262-011-1134-Z

134. Berinstein NL, McNamara M, Nguyen A, Egan J, Wolf GT. Increased immune infiltration and chemokine receptor expression in head and neck epithelial tumors after neoadjuvant immunotherapy with the IRX-2 regimen. Oncoimmunology (2018) 7(5):e1423173. doi: 10.1080/2162402X.2017.1423173

135. Lu H, Dietsch GN, Matthews MA, Yang Y, Ghanekar S, Inokuma M, et al. VTX2337 is a novel TLR8 agonist that activates NK cells and augments ADCC. Clin Cancer Res (2012) 18(2):499-509. doi: 10.1158/1078-0432.CCR-11-1625

136. Ferris RL, Saba NF, Gitlitz BJ, Haddad R, Sukari A, Neupane P, et al. Effect of Adding Motolimod to Standard Combination Chemotherapy and Cetuximab Treatment of Patients With Squamous Cell Carcinoma of the Head and Neck: The Active8 Randomized Clinical Trial. JAMA Oncol (2018) 4(11):1583-8. doi: 10.1001/jamaoncol.2018.1888

137. Noto H, Goto A, Tsujimoto T, Noda M. Cancer risk in diabetic patients treated with metformin: a systematic review and meta-analysis. PloS One (2012) 7(3):e33411. doi: 10.1371/journal.pone.0033411

138. Eikawa S, Nishida M, Mizukami S, Yamazaki C, Nakayama E, Udono H. Immune-mediated antitumor effect by type 2 diabetes drug, metformin. Proc Natl Acad Sci U.S.A. (2015) 112(6):1809-14. doi: 10.1073/pnas.1417636112

139. Amin D, Richa T, Mollaee M, Zhan T, Tassone P, Johnson J, et al. Metformin effects on FOXP3(+) and $\mathrm{CD} 8(+) \mathrm{T}$ cell infiltrates of head and neck squamous cell carcinoma. Laryngoscope (2019) 130(9):E490-8. doi: 10.1002/lary.28336

140. Brahmer J, Reckamp KL, Baas P, Crino L, Eberhardt WE, Poddubskaya E, et al. Nivolumab versus Docetaxel in Advanced Squamous-Cell Non-SmallCell Lung Cancer. N Engl J Med (2015) 373(2):123-35. doi: 10.1056/ NEJMoa1504627

141. Larkin J, Chiarion-Sileni V, Gonzalez R, Grob JJ, Cowey CL, Lao CD, et al. Combined Nivolumab and Ipilimumab or Monotherapy in Untreated Melanoma. N Engl J Med (2015) 373(1):23-34. doi: 10.1056/NEJMoa1504030

142. Nghiem PT, Bhatia S, Lipson EJ, Kudchadkar RR, Miller NJ, Annamalai L, et al. PD-1 Blockade with Pembrolizumab in Advanced Merkel-Cell Carcinoma. N Engl J Med (2016) 374(26):2542-52. doi: 10.1056/ NEJMoa 1603702

143. Ferris RL, Blumenschein GJr., Fayette J, Guigay J, Colevas AD, Licitra L, et al. Nivolumab for Recurrent Squamous-Cell Carcinoma of the Head and Neck. N Engl J Med (2016) 375(19):1856-67. doi: 10.1056/NEJMoa1602252

144. Seiwert TY, Burtness B, Mehra R, Weiss J, Berger R, Eder JP, et al. Safety and clinical activity of pembrolizumab for treatment of recurrent or metastatic squamous cell carcinoma of the head and neck (KEYNOTE-012): an openlabel, multicentre, phase 1b trial. Lancet Oncol (2016) 17(7):956-65. doi: 10.1016/S1470-2045(16)30066-3

145. Segal NH, Ou SI, Balmanoukian A, Fury MG, Massarelli E, Brahmer JR, et al. Safety and efficacy of durvalumab in patients with head and neck squamous cell carcinoma: results from a phase I/II expansion cohort. Eur J Cancer (2019) 109:154-61. doi: 10.1016/j.ejca.2018.12.029

146. Massarelli E, William W, Johnson F, Kies M, Ferrarotto R, Guo M, et al. Combining Immune Checkpoint Blockade and Tumor-Specific Vaccine for Patients With Incurable Human Papillomavirus 16-Related Cancer: A Phase 2 Clinical Trial. JAMA Oncol (2019) 5(1):67-73. doi: 10.1001/ jamaoncol.2018.4051

147. Powell SF, Gold KA, Gitau MM, Sumey CJ, Lohr MM, McGraw SC, et al. Safety and Efficacy of Pembrolizumab With Chemoradiotherapy in Locally Advanced Head and Neck Squamous Cell Carcinoma: A Phase IB Study. J Clin Oncol (2020) 38(21):2427-37. doi: 10.1200/JCO.19.03156

148. Ferris RL, Blumenschein GJr., Fayette J, Guigay J, Colevas AD, Licitra L, et al. Nivolumab vs investigator's choice in recurrent or metastatic squamous cell carcinoma of the head and neck: 2-year long-term survival update of CheckMate 141 with analyses by tumor PD-L1 expression. Oral Oncol (2018) 81:45-51. doi: 10.1016/j.oraloncology.2018.04.008

149. Haddad R, Concha-Benavente F, Blumenschein GJr., Fayette J, Guigay J, Colevas $\mathrm{AD}$, et al. Nivolumab treatment beyond RECIST-defined progression in recurrent or metastatic squamous cell carcinoma of the head and neck in CheckMate 141: A subgroup analysis of a randomized phase 3 clinical trial. Cancer (2019) 125 (18):3208-18. doi: 10.1002/cncr.32190
150. Concha-Benavente F, Srivastava RM, Trivedi S, Lei Y, Chandran U, Seethala $\mathrm{RR}$, et al. Identification of the Cell-Intrinsic and -Extrinsic Pathways Downstream of EGFR and IFNgamma That Induce PD-L1 Expression in Head and Neck Cancer. Cancer Res (2016) 76(5):1031-43. doi: 10.1158/ 0008-5472.CAN-15-2001

151. Jie HB, Srivastava RM, Argiris A, Bauman JE, Kane LP, Ferris RL. Increased PD-1(+) and TIM-3(+) TILs during Cetuximab Therapy Inversely Correlate with Response in Head and Neck Cancer Patients. Cancer Immunol Res (2017) 5(5):408-16. doi: 10.1158/2326-6066.CIR-16-0333

152. Ma W, Concha-Benavente F, Santegoets S, Welters MJP, Ehsan I, Ferris RL, et al. EGFR signaling suppresses type 1 cytokine-induced T-cell attracting chemokine secretion in head and neck cancer. PloS One (2018) 13(9): e0203402. doi: 10.1371/journal.pone. 0203402

153. Trivedi S, Srivastava RM, Concha-Benavente F, Ferrone S, Garcia-Bates TM, Li J, et al. Anti-EGFR Targeted Monoclonal Antibody Isotype Influences Antitumor Cellular Immunity in Head and Neck Cancer Patients. Clin Cancer Res (2016) 22(21):5229-37. doi: 10.1158/1078-0432.CCR-15-2971

154. Ferris RL, Licitra L, Fayette J, Even C, Blumenschein GJr., Harrington KJ, et al. Nivolumab in Patients with Recurrent or Metastatic Squamous Cell Carcinoma of the Head and Neck: Efficacy and Safety in CheckMate 141 by Prior Cetuximab Use. Clin Cancer Res (2019) 25(17):5221-30. doi: 10.1158/ 1078-0432.CCR-18-3944

155. Tumeh PC, Harview CL, Yearley JH, Shintaku IP, Taylor EJ, Robert L, et al. PD-1 blockade induces responses by inhibiting adaptive immune resistance. Nature (2014) 515(7528):568-71. doi: 10.1038/nature13954

156. June CH, O'Connor RS, Kawalekar OU, Ghassemi S, Milone MC. CAR T cell immunotherapy for human cancer. Science (2018) 359(6382):1361-5. doi: 10.1126/science.aar6711

157. Wang X, Riviere I. Manufacture of tumor- and virus-specific T lymphocytes for adoptive cell therapies. Cancer Gene Ther (2015) 22(2):85-94. doi: $10.1038 /$ cgt.2014.81

158. Yang JC, Rosenberg SA. Adoptive T-Cell Therapy for Cancer. Adv Immunol (2016) 130:279-94. doi: 10.1016/bs.ai.2015.12.006

159. Draper LM, Kwong ML, Gros A, Stevanovic S, Tran E, Kerkar S, et al. Targeting of HPV-16+ Epithelial Cancer Cells by TCR Gene Engineered T Cells Directed against E6. Clin Cancer Res (2015) 21(19):4431-9. doi: 10.1158/1078-0432.CCR-14-3341

160. Mercier-Letondal P, Marton C, Deschamps M, Ferrand C, Vauchy C, Chenut $C$, et al. Isolation and Characterization of an HLA-DRB $1^{*} 04$-Restricted HPV16-E7 T Cell Receptor for Cancer Immunotherapy. Hum Gene Ther (2018) 29(10):1202-12. doi: 10.1089/hum.2018.091

161. Ali M, Foldvari Z, Giannakopoulou E, Boschen ML, Stronen E, Yang W, et al. Induction of neoantigen-reactive $\mathrm{T}$ cells from healthy donors. Nat Protoc (2019) 14(6):1926-43. doi: 10.1038/s41596-019-0170-6

162. van der Burg SH. Correlates of immune and clinical activity of novel cancer vaccines. Semin Immunol (2018) 39:119-36. doi: 10.1016/j.smim.2018.04.001

163. van der Burg SH, Arens R, Ossendorp F, van Hall T, Melief CJ. Vaccines for established cancer: overcoming the challenges posed by immune evasion. Nat Rev Cancer (2016) 16(4):219-33. doi: 10.1038/nrc.2016.16

164. Voskens CJ, Sewell D, Hertzano R, DeSanto J, Rollins S, Lee M, et al. Induction of MAGE-A3 and HPV-16 immunity by Trojan vaccines in patients with head and neck carcinoma. Head Neck (2012) 34(12):173446. doi: 10.1002/hed.22004

165. Schuler PJ, Harasymczuk M, Visus C, Deleo A, Trivedi S, Lei Y, et al. Phase I dendritic cell p53 peptide vaccine for head and neck cancer. Clin Cancer Res (2014) 20(9):2433-44. doi: 10.1158/1078-0432.CCR-13-2617

166. Kenter GG, Welters MJ, Valentijn AR, Lowik MJ, Berends-van der Meer DM, Vloon AP, et al. Vaccination against HPV-16 oncoproteins for vulvar intraepithelial neoplasia. N Engl J Med (2009) 361(19):1838-47. doi: 10.1056/ NEJMoa0810097

167. van Poelgeest MI, Welters MJ, Vermeij R, Stynenbosch LF, Loof NM, Berends-van der Meer DM, et al. Vaccination against Oncoproteins of HPV16 for Noninvasive Vulvar/Vaginal Lesions: Lesion Clearance Is Related to the Strength of the T-Cell Response. Clin Cancer Res (2016) 22 (10):2342-50. doi: 10.1158/1078-0432.CCR-15-2594

168. Hilf N, Kuttruff-Coqui S, Frenzel K, Bukur V, Stevanovic S, Gouttefangeas C, et al. Actively personalized vaccination trial for newly diagnosed glioblastoma. Nature (2019) 565(7738):240-5. doi: 10.1038/s41586-018-0810-y 
169. Hu Z, Ott PA, Wu CJ. Towards personalized, tumour-specific, therapeutic vaccines for cancer. Nat Rev Immunol (2018) 18(3):168-82. doi: 10.1038/ nri.2017.131

170. Sahin U, Derhovanessian E, Miller M, Kloke BP, Simon P, Lower M, et al. Personalized RNA mutanome vaccines mobilize poly-specific therapeutic immunity against cancer. Nature (2017) 547(7662):222-6. doi: 10.1038/nature23003

171. Demaria S, Golden EB, Formenti SC. Role of Local Radiation Therapy in Cancer Immunotherapy. JAMA Oncol (2015) 1(9):1325-32. doi: 10.1001/ jamaoncol.2015.2756

172. Shaverdian N, Lisberg AE, Bornazyan K, Veruttipong D, Goldman JW, Formenti SC, et al. Previous radiotherapy and the clinical activity and toxicity of pembrolizumab in the treatment of non-small-cell lung cancer: a secondary analysis of the KEYNOTE-001 phase 1 trial. Lancet Oncol (2017) 18(7):895-903. doi: 10.1016/S1470-2045(17)30380-7

173. Bonomo P, Desideri I, Loi M, Mangoni M, Sottili M, Marrazzo L, et al. Anti PD-L1 DUrvalumab combined with Cetuximab and RadiOtherapy in locally advanced squamous cell carcinoma of the head and neck: A phase I/II study (DUCRO). Clin Transl Radiat Oncol (2018) 9:42-7. doi: 10.1016/ j.ctro.2018.01.005

174. Bahig H, Aubin F, Stagg J, Gologan O, Ballivy O, Bissada E, et al. Phase I/II trial of Durvalumab plus Tremelimumab and stereotactic body radiotherapy for metastatic head and neck carcinoma. BMC Cancer (2019) 19(1):68. doi: 10.1186/s12885-019-5266-4

175. Yu Y, Lee NY. JAVELIN Head and Neck 100: a Phase III trial of avelumab and chemoradiation for locally advanced head and neck cancer. Future Oncol (2019) 15(7):687-94. doi: 10.2217/fon-2018-0405

176. Elbers JBW, Al-Mamgani A, Tesseslaar MET, van den Brekel MWM, Lange $\mathrm{CAH}$, van der Wal JE, et al. Immuno-radiotherapy with cetuximab and avelumab for advanced stage head and neck squamous cell carcinoma: Results from a phase-I trial. Radiother Oncol (2020) 142:79-84. doi: 10.1016/.radonc.2019.08.007

177. Vermeer DW, Spanos WC, Vermeer PD, Bruns AM, Lee KM, Lee JH. Radiation-induced loss of cell surface CD47 enhances immune-mediated clearance of human papillomavirus-positive cancer. Int J Cancer (2013) 133 (1):120-9. doi: 10.1002/ijc.28015

178. Advani R, Flinn I, Popplewell L, Forero A, Bartlett NL, Ghosh N, et al. CD47 Blockade by Hu5F9-G4 and Rituximab in Non-Hodgkin's Lymphoma. N Engl J Med (2018) 379(18):1711-21. doi: 10.1056/NEJMoa1807315

179. Logtenberg MEW, Jansen JHM, Raaben M, Toebes M, Franke K, Brandsma AM, et al. Glutaminyl cyclase is an enzymatic modifier of the CD47SIRPalpha axis and a target for cancer immunotherapy. Nat Med (2019) 25(4):612-9. doi: 10.1038/s41591-019-0356-z

180. Hanoteau A, Newton JM, Krupar R, Huang C, Liu HC, Gaspero A, et al. Tumor microenvironment modulation enhances immunologic benefit of chemoradiotherapy. J Immunother Cancer (2019) 7(1):10. doi: 10.1186/ s40425-018-0485-9

181. Beyranvand Nejad E, van der Sluis TC, van Duikeren S, Yagita H, Janssen GM, van Veelen PA, et al. Tumor Eradication by Cisplatin Is Sustained by CD80/86-Mediated Costimulation of CD8+ T Cells. Cancer Res (2016) 76 (20):6017-29. doi: 10.1158/0008-5472.CAN-16-0881

182. van der Sluis TC, van Duikeren S, Huppelschoten S, Jordanova ES, Beyranvand Nejad E, Sloots A, et al. Vaccine-induced tumor necrosis factor-producing $\mathrm{T}$ cells synergize with cisplatin to promote tumor cell death. Clin Cancer Res (2015) 21(4):781-94. doi: 10.1158/1078-0432.CCR-14-2142

183. Goh AR, Shin SP, Jung NR, Ryu CH, Eom HS, Lee JH, et al. Low-dose cisplatin converts the tumor microenvironment into a permissive state for HSVtk-induced antitumor immunity in HPV16-related tonsillar carcinoma. Cancer Lett (2015) 356(2 Pt B):743-50. doi: 10.1016/j.canlet.2014.10.022

184. Dorta-Estremera S, Hegde VL, Slay RB, Sun R, Yanamandra AV, Nicholas C, et al. Targeting interferon signaling and CTLA- 4 enhance the therapeutic efficacy of anti-PD-1 immunotherapy in preclinical model of HPV(+) oral cancer. J Immunother Cancer (2019) 7(1):252. doi: 10.1186/s40425-019-0728-4

185. Cillo AR, Kurten CHL, Tabib T, Qi Z, Onkar S, Wang T, et al. Immune Landscape of Viral- and Carcinogen-Driven Head and Neck Cancer. Immunity (2020) 52(1):183-99.e189. doi: 10.1016/j.immuni.2019.11.014
186. Ijsselsteijn ME, van der Breggen R, Farina Sarasqueta A, Koning F, de Miranda N. A 40-Marker Panel for High Dimensional Characterization of Cancer Immune Microenvironments by Imaging Mass Cytometry. Front Immunol (2019) 10:2534. doi: 10.3389/fimmu.2019.02534

187. Welters MJ, van der Sluis TC, van Meir H, Loof NM, van Ham VJ, van Duikeren S, et al. Vaccination during myeloid cell depletion by cancer chemotherapy fosters robust $\mathrm{T}$ cell responses. Sci Transl Med (2016) 8 (334):334ra352. doi: 10.1126/scitranslmed.aad8307

188. Melief CJM, Welters MJP, Vergote I, Kroep JR, Kenter GG, Ottevanger PB, et al. Strong vaccine responses during chemotherapy are associated with prolonged cancer survival. Sci Transl Med (2020) 12(535):eaaz8235. doi: 10.1126/scitranslmed.aaz8235

189. Abdulrahman Z, De Miranda NF, Van Esch EM, De Vos van Steenwiik PJ, Nijman HW, Welters MJP, et al. A pre-existing inflammatory immune microenvironment predicts the clinical response of vulvar high-grade squamous intraepithelial lesions to therapeutic HPV16 vaccination. J Immunother Cancer (2020) 8(1):e000563. doi: 10.1136/jitc-2020-000563

190. Duhen T, Duhen R, Montler R, Moses J, Moudgil T, de Miranda NF, et al. Coexpression of $\mathrm{CD} 39$ and $\mathrm{CD} 103$ identifies tumor-reactive $\mathrm{CD} 8 \mathrm{~T}$ cells in human solid tumors. Nat Commun (2018) 9(1):2724. doi: 10.1038/s41467-018-05072-0

191. Gros A, Robbins PF, Yao X, Li YF, Turcotte S, Tran E, et al. PD-1 identifies the patient-specific $\mathrm{CD} 8(+)$ tumor-reactive repertoire infiltrating human tumors. J Clin Invest (2014) 124(5):2246-59. doi: 10.1172/JCI73639

192. Parkhurst M, Gros A, Pasetto A, Prickett T, Crystal JS, Robbins P, et al. Isolation of T-Cell Receptors Specifically Reactive with Mutated TumorAssociated Antigens from Tumor-Infiltrating Lymphocytes Based on CD137 Expression. Clin Cancer Res (2017) 23(10):2491-505. doi: 10.1158/10780432.CCR-16-2680

193. Ye Q, Song DG, Poussin M, Yamamoto T, Best A, Li C, et al. CD137 accurately identifies and enriches for naturally occurring tumor-reactive $\mathrm{T}$ cells in tumor. Clin Cancer Res (2014) 20(1):44-55. doi: 10.1158/10780432.CCR-13-0945

194. Hung K, Hayashi R, Lafond-Walker A, Lowenstein C, Pardoll D, Levitsky H. The central role of CD4(+) T cells in the antitumor immune response. J Exp Med (1998) 188(12):2357-68. doi: 10.1084/jem.188.12.2357

195. Levitsky HI, Lazenby A, Hayashi RJ, Pardoll DM. In vivo priming of two distinct antitumor effector populations: the role of MHC class I expression. J Exp Med (1994) 179(4):1215-24. doi: 10.1084/jem.179.4.1215

196. Shankaran V, Ikeda H, Bruce AT, White JM, Swanson PE, Old LJ, et al. IFNgamma and lymphocytes prevent primary tumour development and shape tumour immunogenicity. Nature (2001) 410(6832):1107-11. doi: $10.1038 / 35074122$

197. Hunder NN, Wallen H, Cao J, Hendricks DW, Reilly JZ, Rodmyre R, et al. Treatment of metastatic melanoma with autologous CD4+ T cells against NY-ESO-1. N Engl J Med (2008) 358(25):2698-703. doi: 10.1056/ NEJMoa0800251

198. Quezada SA, Simpson TR, Peggs KS, Merghoub T, Vider J, Fan X, et al. Tumor-reactive CD4(+) T cells develop cytotoxic activity and eradicate large established melanoma after transfer into lymphopenic hosts. J Exp Med (2010) 207(3):637-50. doi: 10.1084/jem.20091918

199. Tran E, Turcotte S, Gros A, Robbins PF, Lu YC, Dudley ME, et al. Cancer immunotherapy based on mutation-specific CD4+ T cells in a patient with epithelial cancer. Science (2014) 344(6184):641-5. doi: 10.1126/ science. 1251102

Conflict of Interest: The authors declare that the research was conducted in the absence of any commercial or financial relationships that could be construed as a potential conflict of interest.

Copyright (c) 2020 Welters, Santegoets and van der Burg. This is an open-access article distributed under the terms of the Creative Commons Attribution License (CC BY). The use, distribution or reproduction in other forums is permitted, provided the original author(s) and the copyright owner(s) are credited and that the original publication in this journal is cited, in accordance with accepted academic practice. No use, distribution or reproduction is permitted which does not comply with these terms. 